\title{
Article
}

\section{In Leishmania major, the Homolog of the Oncogene PES1 May Play a Critical Role in Parasite Infectivity}

\author{
Miriam Algarabel ${ }^{1,+}$, Celia Fernández-Rubio ${ }^{1,+} \mathbb{C}$, Katerina Musilova ${ }^{1}$, José Peña-Guerrero ${ }^{1} \mathbb{C}$, Andrés Vacas ${ }^{1}{ }^{\mathbb{D}}$, \\ Esther Larrea $^{2}$ and Paul A. Nguewa ${ }^{1, *(D)}$ \\ 1 Department of Microbiology and Parasitology, ISTUN Instituto de Salud Tropical, IdiSNA, \\ Instituto de Investigación Sanitaria de Navarra, Universidad de Navarra, E-31008 Pamplona, Spain; \\ malgarabel@alumni.unav.es (M.A.); cfdezrubio@unav.es (C.F.-R.); kmusilova@alumni.unav.es (K.M.); \\ jpena.1@alumni.unav.es (J.P.-G.); avacas@alumni.unav.es (A.V.) \\ 2 ISTUN Instituto de Salud Tropical, IdiSNA, Instituto de Investigación Sanitaria de Navarra, \\ Universidad de Navarra, E-31008 Pamplona, Spain; elarrea@unav.es \\ * Correspondence: panguewa@unav.es \\ + These authors have contributed equally to this work.
}

Citation: Algarabel, M.; FernándezRubio, C.; Musilova, K.; Peña-Guerrero, J.; Vacas, A.; Larrea, E.; Nguewa, P.A. In Leishmania major, the Homolog of the Oncogene PES1 May Play a Critical Role in Parasite Infectivity. Int. J. Mol. Sci. 2021, 22, 12592. https://doi.org/ $10.3390 /$ ijms222212592

Academic Editor: Sherif T. S. Hassan

Received: 30 September 2021

Accepted: 15 November 2021

Published: 22 November 2021

Publisher's Note: MDPI stays neutral with regard to jurisdictional claims in published maps and institutional affiliations.

Copyright: (C) 2021 by the authors Licensee MDPI, Basel, Switzerland. This article is an open access article distributed under the terms and conditions of the Creative Commons Attribution (CC BY) license (https:// creativecommons.org/licenses/by/ $4.0 /)$.

\begin{abstract}
Leishmaniasis is a neglected tropical disease caused by Leishmania spp. The improvement of existing treatments and the discovery of new drugs remain ones of the major goals in control and eradication of this disease. From the parasite genome, we have identified the homologue of the human oncogene PES1 in Leishmania major (LmjPES). It has been demonstrated that PES1 is involved in several processes such as ribosome biogenesis, cell proliferation and genetic transcription. Our phylogenetic studies showed that LmjPES encodes a highly conserved protein containing three main domains: PES N-terminus (shared with proteins involved in ribosomal biogenesis), BRCT (found in proteins related to DNA repair processes) and MAEBL-type domain (C-terminus, related to erythrocyte invasion in apicomplexan). This gene showed its highest expression level in metacyclic promastigotes, the infective forms; by fluorescence microscopy assay, we demonstrated the nuclear localization of LmjPES protein. After generating mutant parasites overexpressing LmjPES, we observed that these clones displayed a dramatic increase in the ratio of cell infection within macrophages. Furthermore, BALB/c mice infected with these transgenic parasites exhibited higher footpad inflammation compared to those inoculated with non-overexpressing parasites.
\end{abstract}

Keywords: Leishmania; pescadillo; PES; ribosome biogenesis; infection

\section{Introduction}

Estimates suggest that approximately one tenth of the world's population lives in extreme poverty (USD <1.90/day), mostly affected by Neglected Tropical Diseases (NTDs) [1]. Disability Adjusted Life Years (DALYs) related to NTDs are constituted for $56 \%$ by Years Lost due to Disability (YLD) and for $44 \%$ by Years of Life Lost (YLL) [2]. Some NTDs that cause significant mortality, such as leishmaniasis and trypanosomiasis, require medical supervision for their control and depend on expensive and toxic drugs with long courses of treatment [1]. For most NTDs, the development of new drugs is predominantly or exclusively supported by "charitable" funding from public or philanthropic organizations, with little or no contribution from the pharmaceutical industry [3]. The World Health Organization (WHO) recognizes up to 20 diverse illnesses as NTDs, including trypanosomatid-caused pathologies. Among them, leishmaniasis is a group of vector-borne diseases produced by protozoan parasites from the Leishmania genus. Over 90 sandfly species are known to transmit Leishmania parasites. Clinical manifestations range from self-healing cutaneous lesions to visceral forms which can cause death if untreated. According to the Global Health Observatory, out of 200 territories reporting to WHO in 2020, 98 were endemic for leishmaniasis: 71 countries are endemic for both visceral leishmaniasis (VL) and cutaneous leishmaniasis (CL), 8 for VL only, and 19 countries 
are endemic for CL only [4]. The treatment of leishmaniasis depends on several factors including immune status of the host, parasite specie and geographic location. In general, healing requires an immunocompetent system [5]. First-line treatments comprise pentavalent antimonials. However, their effectiveness has dramatically decreased due to the appearance of resistances. Alternative chemotherapy such as Paromomycin, Amphotericin B, Pentamidine and Allopurinol showed similar problems [6]. Currently, the only available oral treatment is Miltefosine, for which resistances have also been reported [7,8]. Since leishmaniasis is considered as an NTD, in spite of the large population suffering it the funds for the development of treatment options remain limited; thus, the development of newer therapeutic options is an urgent need. Consequently, research in the field of drug development is directed towards the study of target molecules for the control of this disease [9]. The availability of the sequenced genome from several species of Leishmania has allowed the identification of the Pescadillo (PES) homologue. This oncogene is conserved among eukaryotes and has been mainly related to ribosomal biogenesis as part of the PeBoW complex [10-12]. Besides this process, PES involvement has been demonstrated in other important biological routes, including cell proliferation $[13,14]$, embryo development [15] and gene transcription [16]. In addition, high levels of PES have been detected in several tumours such as colon, breast, or prostate cancer [17-20]. On the other hand, the PES homologue detected in the fungal pathogen Candida albicans was demonstrated to be an essential switch for the yeast-inducing stage, which is responsible for fungal spread throughout the body [21]. In relation to the virulence process, an orthologue of PES has been reported in Plasmodium falciparum, exhibiting a protein expression level dependent on parasite stage [22]. Therefore, PES participates in several biological events and is mainly considered as part of the protein set in charge of ribosome biogenesis, a process that takes place in the nucleolus. The synthesis of ribosomes is one of the most energetically demanding cellular processes and involves highly coordinated steps, including the synthesis of ribosomal proteins (RPs) in the cytoplasm, the synthesis and modification of ribosomal RNAs, the importation of rRNAs into the nucleus, the assembly of RPs and rRNAs in the nucleoplasm and the transportation of the two mature subunits (40S and 60S) into the cytoplasm [23,24]. Some findings have shown that the nucleolus is also implicated in biological events, including the cellular stress response [25]. The structure and function of the nucleolus have been mainly analysed in vertebrates and yeast; the knowledge of this nuclear body in trypanosomatid protozoan parasites still needs to be explored [26]. Since Leishmania spp. are heteroxenous parasites, they display several development stages and morphological changes, regulated by differential gene expression, in response to the different stress environments present in each host $[27,28]$. For instance, it has been observed that nutritional starvation found during the metacyclogenesis process can induce the dispersion of nucleolar material into the parasite nucleoplasm [29]. Our work was focused on the discovery of the homologue of PES in Leishmania major, and we also attempted to shed some light on its involvement in parasite biology and its role as a therapeutic target against pathogenic protozoan.

\section{Results}

\subsection{LmjPES Is Highly Conserved among Trypanosomatid Cluster}

LmjPES (LmjF.04.0810) sequence was retrieved from gene DB as a protein-coding gene in Leishmania major. This gene is located on chromosome 4 in all the Leishmania species and is highly conserved in trypanosomatids. It is found on chromosome 9 and 8 in T. brucei and T. cruzi, respectively [30,31]. On the other hand, the identity analysis showed that $L$. major gene-sequence identity was higher than $85 \%$ and $63 \%$ when compared to $L$. mexicana or L. braziliensis, and L. donovani or L. infantum, respectively. In addition, such an identity was also higher than $60 \%$ when compared to Trypanosoma spp. genes. LmjPES encodes a protein of 671 amino acids with an estimated molecular mass of $77.29 \mathrm{kDa}$ and a theoretical $\mathrm{pI}$ of 9.69. This protein was predicted to contain two main conserved domains: an N-terminal pescadillo-like protein (NPLP) domain and a BRCT domain 
(Figure 1A) as found through their secondary structure analysis. To our knowledge, LmjPES is the first reported protein harboring a BRCT-domain in Leishmania spp. Protein sequence alignment showed more than $90 \%$ of similarity among Leishmania species, with L. infantum and L. donovani the most divergent species (Supplementary Figure S1). These alignments revealed that PES homologue is a conserved protein in the trypanosomatids cluster (Figure 1B), since Trypanosoma spp. conserved $82 \%$ of their sequence identity when compared to Leishmania spp. The sequence analysis allowed confirmation of the aforementioned NPLP and BRCT domains (Figure 1A). On the other hand, no putative myristoylation signal peptide or Glycosylphosphatidilinositol (GPI)-anchor was detected within the LmjPES sequence. No transmembrane helix was found along the protein. Regarding protein-protein motifs, two coiled regions were identified, covering 60 and 20 amino acids each (Figure 1A). A disordered region was initially described in the LmjPES C-terminal region (residues 405-671); however, a gap junction-related Neuromodulin_Ndomain (MAEBL) (residues 499-665) was also recently located at C-terminus. Furthermore, there are two nuclear localization signals (NLS) at the C-terminal region, along the MAEBLdomain (Figure 1A). Gene Ontology analysis (GO terms) mainly showed LmjPES as a putative ribosomal protein as well as an RNA binding protein, among others molecular functions. Regarding biological processes, GO terms predicted LmjPES would be involved in cell proliferation, RNA processing, and the ribosomal subunit biogenesis and cell cycle. Furthermore, the phylogenetic analysis revealed that PES orthologues are not restricted to kinetoplastid organisms. The alignment of PES orthologous sequences showed high conservation levels among eukaryotic organisms. PES orthologues from trypanosomatids and from non-kinetoplastid organisms (Xaenopus laevis, Dario rerio, Homo sapiens, Mus musculus, Plasmodium falciparum and Saccharomyces cerevisiae) were used to reconstruct the PES phylogram (Figure 1B). Consistent with our study, PES from Leishmania species belongs to a tight and conserved clade where PES orthologs from the other Kinetoplastea species were included. Interestingly, the phylogenetic tree showed that PES orthologue proteins from non-kinetoplastid organisms could be clustered externally to the tightly organized kinetoplastid branches. H. sapiens PES1 and S. cerevisiae Nop7 belong to the same branch, in which X. laevis and D. rerio PES share the same cluster (Figure 1B). Based on the homology observed amongst PES sequences from trypanosomatids, we selected Leishmania major (LmjPES) to perform further experiments.

\subsection{LmjPES Is a Protein Located in the Nucleus}

The secondary structure analysis of PES homologue in Leishmania predicted the presence of NLS, and therefore, a nuclear location. To validate such a prediction, the plasmid pXG-mCherry34-LmjPES (Figure 2B) was generated through the N-terminal fusion of LmjPES to the red fluorescent fusion protein mCherry34 (Figure 2A). LmjPES sequence was obtained from L. major cDNA using the primers LmjPESmCherryFw and LmjPESmCherryRv. The subsequent nucleotide sequence was compared to the TriTrypDB Lmj.04.0810 annotated entry by sequencing. More than $99 \%$ sequence identity was found, and no genetic variations were identified between both sequences. Despite the two differences being detected at positions 178 and 550, these double-nucleotide polymorphisms did not change the translated protein sequence (Supplementary Figure S2).

Fluorescent parasites harbouring pXG-mCherry34 and pXG-mCherry34-LmjPES constructs are depicted in Figure 2. Leishmania parasites with pXG-mCherry34, used as a control, can be seen in the top lane while parasites with pXG-mCherry34-LmjPES are present in the bottom lane (Figure 2C). As observed in the control parasites, red fluorescence did not show specific organelle localization, whereas in cells transfected with pXG-mCherry34-LmjPES plasmid, LmjPES fusion protein can clearly be seen within the nucleus (Figure 2C). 
A

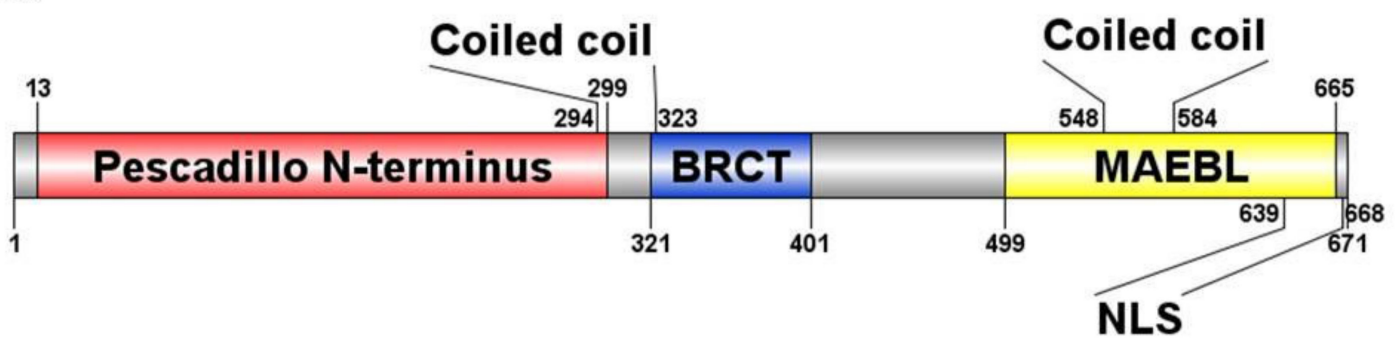

B

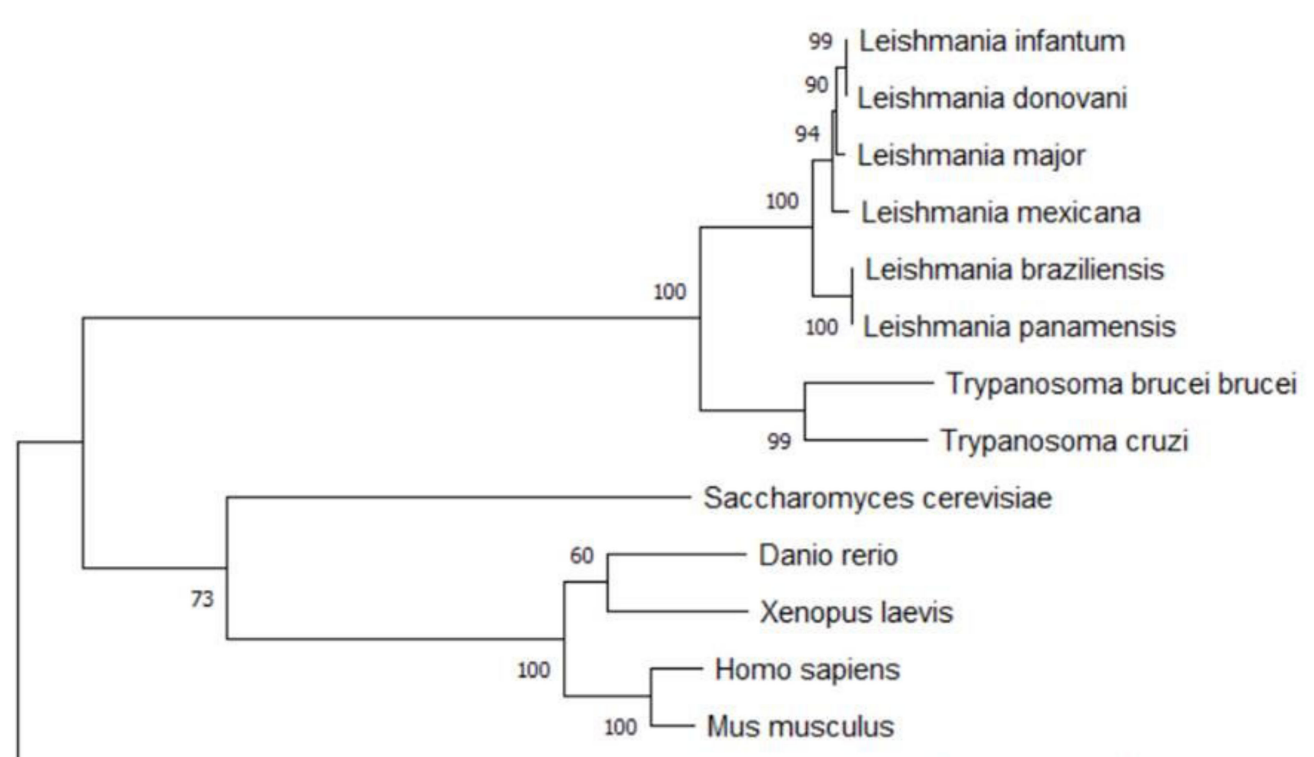

Plasmodium falciparum

0.20

Figure 1. LmjPES is highly conserved among trypanosomatid cluster. (A) Schematic representation of the predicted catalytically relevant regions and domains of LmjPES. (B) Phylogenetic analysis of LmjPES. Tree was rooted using the sequence of the hypothetical protein C923_03267 from Plasmodium falciparum. Protein sequences of PES trypanosomatid orthologues (accession numbers: XP_001561761.1, XP_010703722.1, XP_003871849.1, XP_888589.1, A4HS78.1, AYU75861.1, XP_827157.1, RNF20479.1) and PES proteins form Danio rerio (NP_571105.3), Xenopus laevis (NP_001080557.1), Homo sapiens (NP_055118.1), Mus musculus (NP_075027.1) and Saccharomyces cervisiae (PJP07134.1) were used to generate the phylogram.

\subsection{LmjPES Gene Expression was Highly Expressed in the Metacyclic Stage}

Having described the presence of the PES homologue in Leishmania parasites, we aimed to study the expression level of this gene along the promastigote life cycle. For this purpose, qPCR analysis was performed and PES homologue (LmjPES) expression was quantified in both procyclic and metacyclic promastigotes. As shown in Figure 3, LmjPES metacyclic forms selected by PNA method exhibited the highest expression levels of this gene, more than eight times higher $(8.14 \pm 0.11)$ than those observed in procyclic ones. The promastigotes negative-selected by PNA method corresponded to the parasite stage, which is able to infect immune cells. Therefore, LmjPES expression might be related to infectivity. 
A

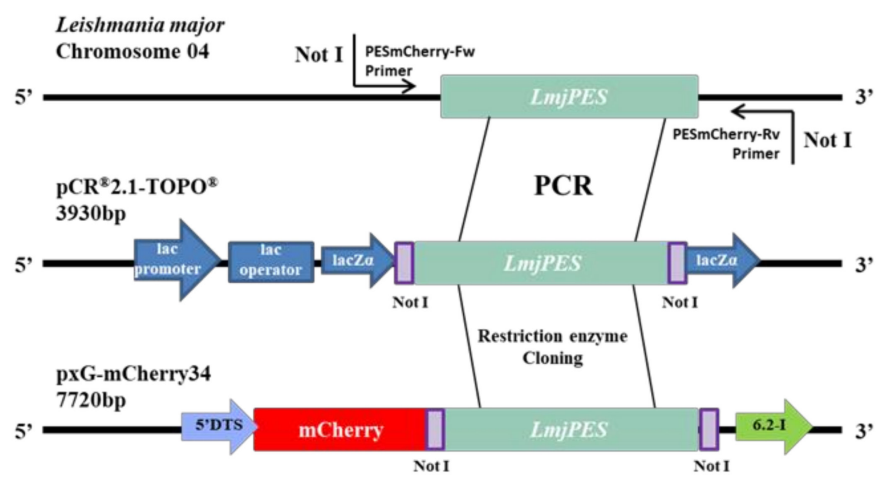

$\mathrm{C}$
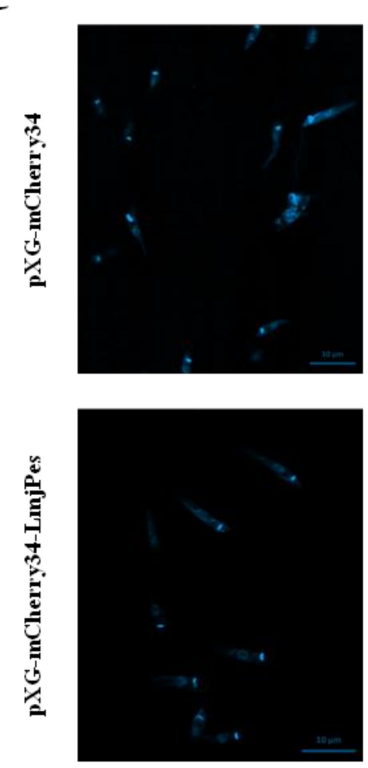

mCherry
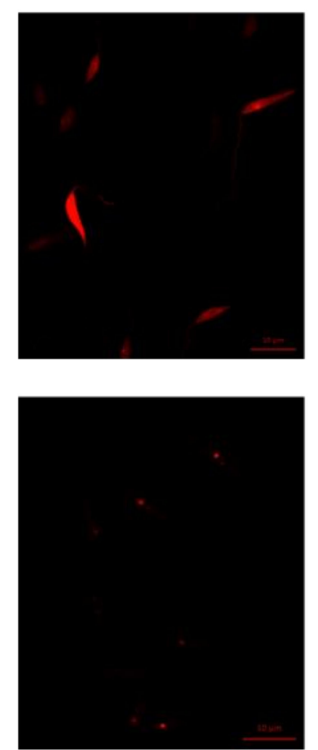

B
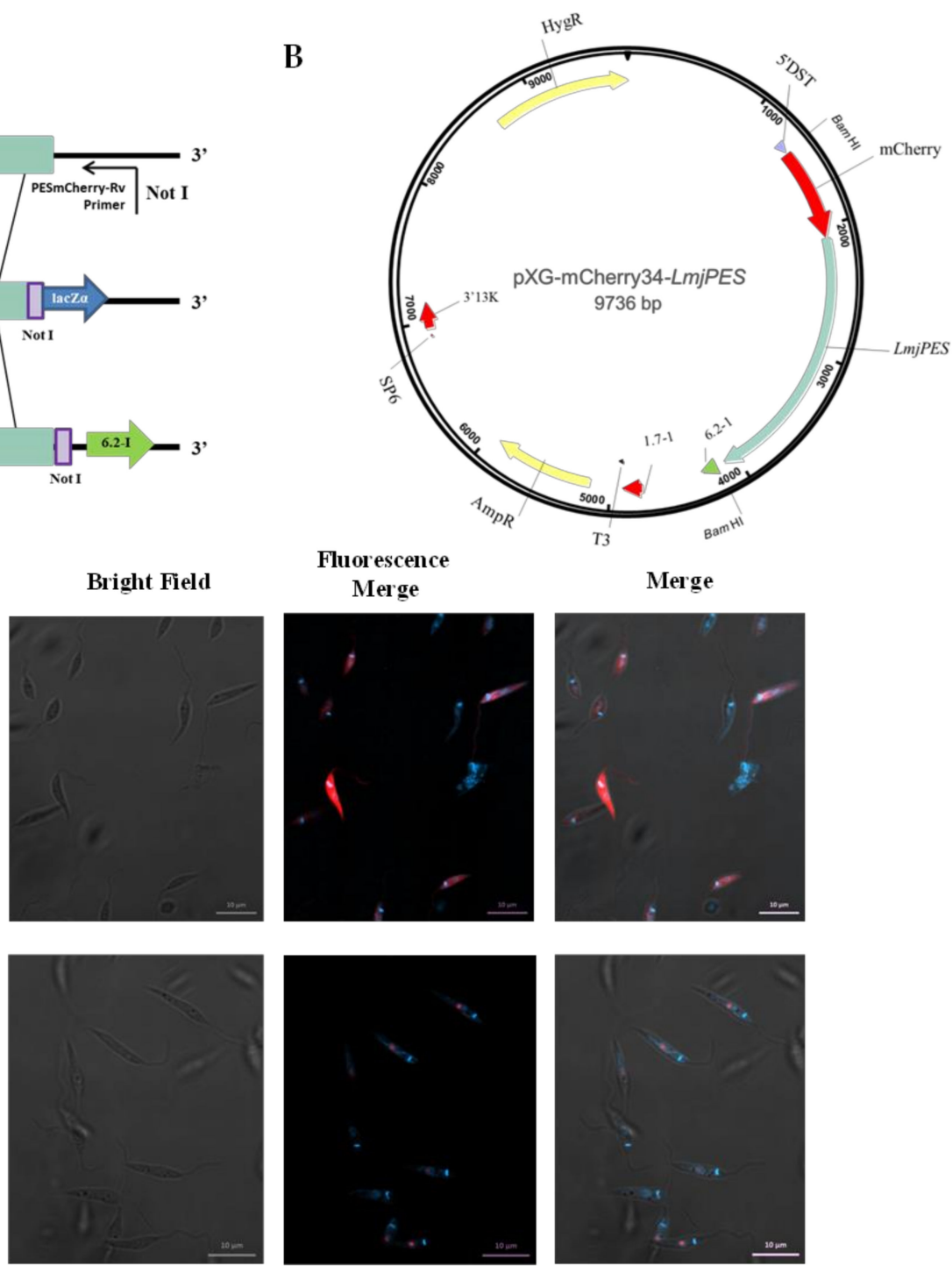

Merge
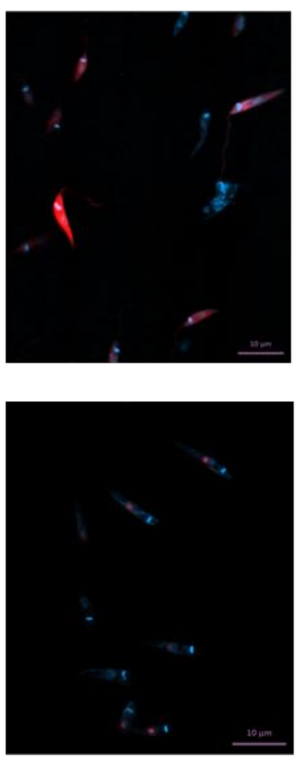
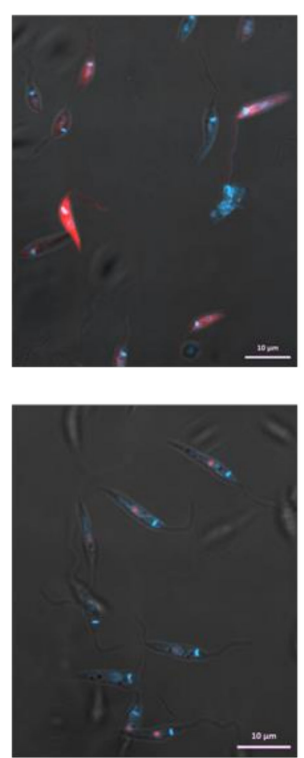

Figure 2. LmjPES is a protein located in the nucleus. (A) Schematic representation of the approach to generate the LmjPES red fluorescent protein. (B) Map of the plasmid carrying the genetic sequence of the red fluorescent protein mCherry fused to LmjPES gene. (C) L. major promastigotes expressing control mCherry34 (top lane) and mCherry34-LmjPES (bottom lane) fusion proteins.

\subsection{LmjPES Overexpression Increased the Infectivity Rates In Vitro}

Since LmjPES reached its highest gene expression level in the metacyclic stage, we decided to elucidate the role of this gene in the parasites' acquisition of infectivity and in the progression of the disease by evaluating cells harbouring episomally overexpressed LmjPES. The episomal expression vector pXG-HygR-LmjPES was constructed by the strategy previously described (Figure 4A), and used to overexpress LmjPES in L. major parasites (Figure $4 \mathrm{~B}$ ). The qPCR gene expression measurement of LmjPES in the developed transgenic L. major strain allowed us to select two clones (pXG-HygR-LmjPES 1 and pXG-HygRLmjPES 2, also named clone 1 and clone 2, respectively) which exhibited similar rates of overexpression (6.36 \pm 0.24 and $7.62 \pm 0.10$, respectively) (Figure $4 \mathrm{C})$. Growth curves and cytometry analyses demonstrated the LmjPES-overexpressing parasites displayed a growth curve and cell cycle profile similar to control parasites (data not shown). 


\section{LmjPES}

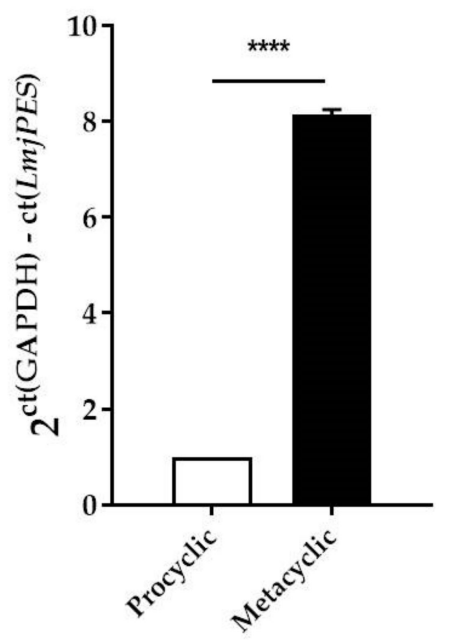

Figure 3. $L m j P E S$ gene expression is highly expressed in the metacyclic stage. LmjPES relative gene expression in procyclic and metacyclic promastigotes from Leishmania major. Bars represent gene expression mean fold change $( \pm \mathrm{SD})$ from three independent experiments $(* * * *<0.0001)$.

A

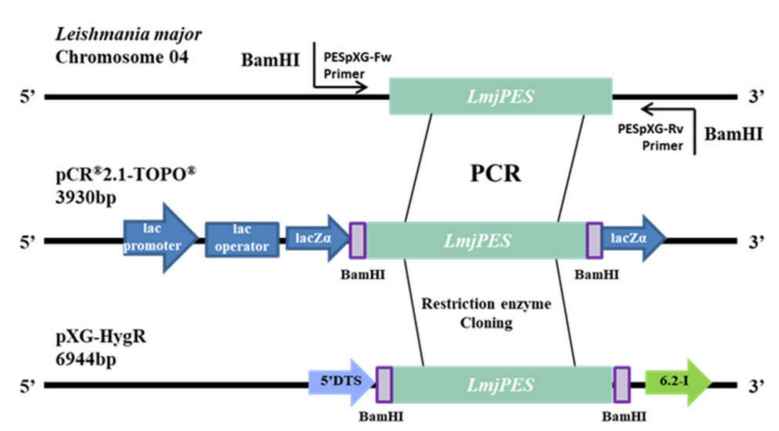

B

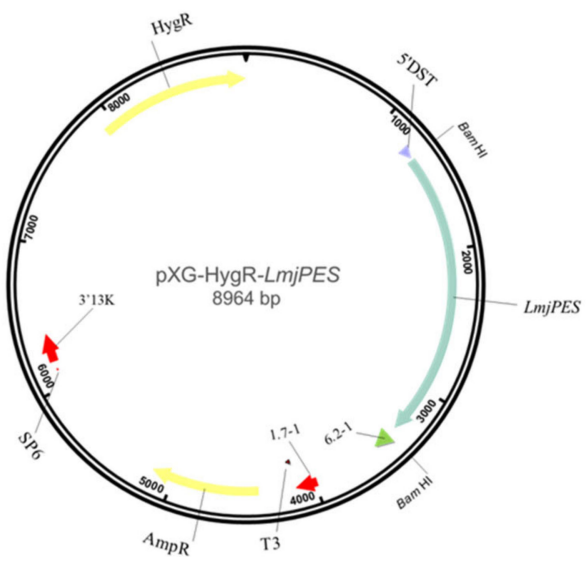

C

LmjPES

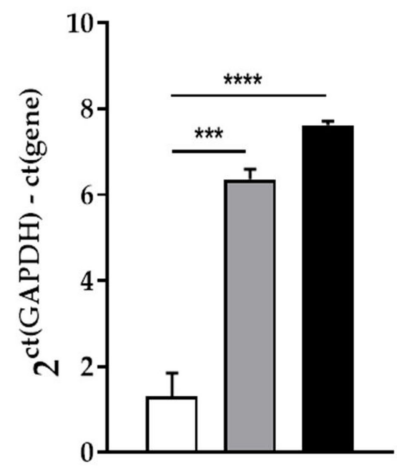

$\square$ pXG-HygR

$\square$ pXG-HygR-LmiPES 1

- pXG-HygR-LmiPES 2

Figure 4. Generation of Leishmania major strains overexpressing LmjPES. (A) Schematic representation of the approach to clone LmjPES into the pXG-HygR overexpression plasmid. (B) Map of the episomal plasmid carrying the LmjPES sequence used to generate overexpressing parasites (C) LmjPES gene expression level of two LmjPES-overexpressing L. major strains (pXG-HygR-LmjPES1 and pXG-HygR-LmjPES2) compared to L. major control (pXG-HygR) parasites $\left({ }^{* * *} p<0.001\right.$; $* * * * p<0.0001)$. 
Peritoneal macrophages obtained from BALB/c mice were infected with Control (harboring pXG-HygR plasmid) and LmjPES-overexpressing metacyclic promastigotes at a 20:1 (promastigotes:macrophage) ratio. Three hours post-infection, significant differences were observed in the percentage of infected cells $(20.86 \pm 3.42$ for control vs. $34.16 \pm 3.81$ in clone 1 and $39.47 \pm 5.67$ in clone 2) (Figure $5 \mathrm{~A}$ ) and in the number of amastigotes per infected cell between Control and overexpressing parasites (control: $78.33 \pm 5.86$ vs. clone 1 : $160.00 \pm 2.83$ and clone 2: $212.00 \pm 4.24$ ) (Figure 5B). In fact, the highest infection matched clone 2 (pXG-HygR-LmjPES2), which showed the highest level of LmjPES gene expression. Six hours post-infection, the percentage of infected macrophages as well as the number of intracellular amastigotes remained higher in LmjPES-overexpressing strain infections ( $30.50 \pm 5.70$ vs. $85.04 \pm 3.47$ and $96.50 \pm 0.71$ vs. $421.00 \pm 14.14$, respectively) (Figure 5A,B). Figure 5C illustrates the nuclei of macrophages and intracellular amastigotes that were stained with Giemsa to quantify the infection by microscopy analysis.

A

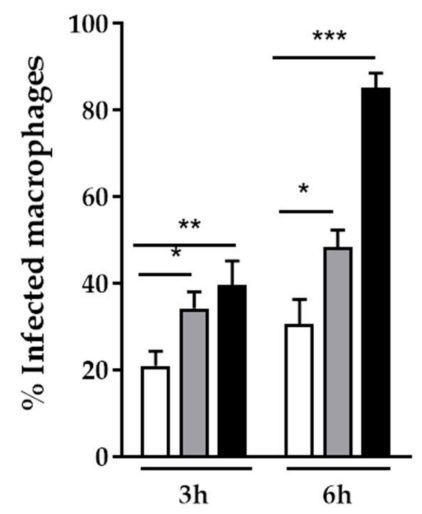

B

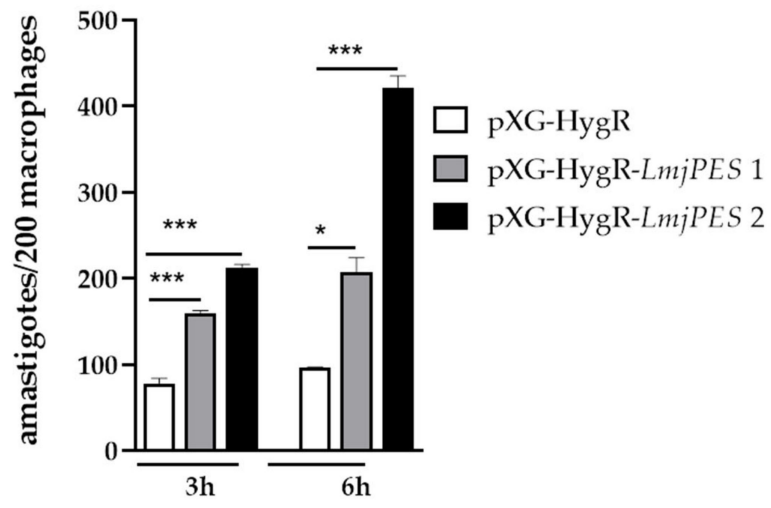

C
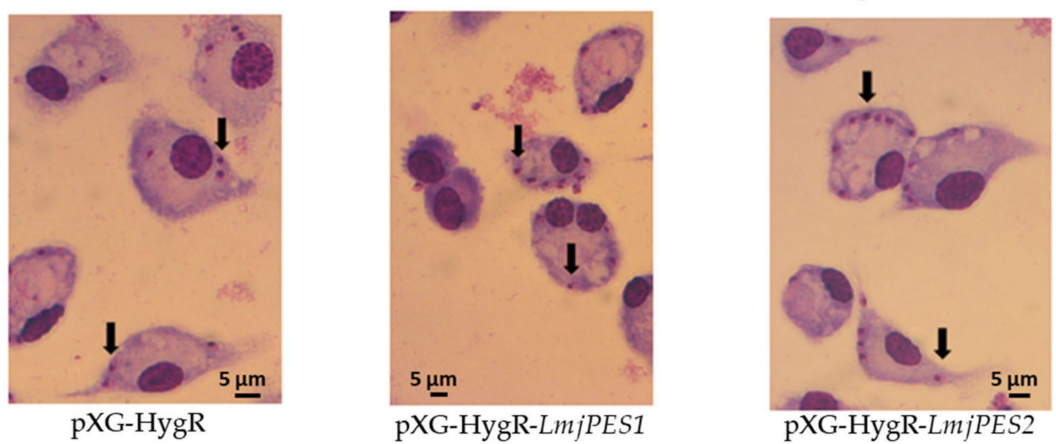

Figure 5. LmjPES overexpression increases infectivity rates in vitro. Analyses were conducted with two LmjPESoverexpressing L. major strains (pXG-HygR-LmjPES1 and pXG-HygR-LmjPES2). (A) The percentage of infected macrophages and (B) the number of amastigotes per 200 infected cells were evaluated by microscopy counting after Giemsa staining at 3 and $6 \mathrm{~h}$ post-infection. (C) The observed changes in the infectivity rate throughout the in vitro infection caused by overexpressing and non-overexpressing parasites were graphed for one representative experiment. Solid black arrows indicate Giemsa-stained amastigotes. Data represent the means $( \pm \mathrm{SD})$ from the triplicates of at least three independent experiments $\left({ }^{*} p<0.05,{ }^{* *} p<0.01,{ }^{* * *} p<0.001\right)$.

\subsection{LmjPES Overexpressing Parasites Exhibited Higher and Faster Footpad Inflammation in $B A L B / c$ Mice than Non-Overexpressing Parasites}

To evaluate the role of LmjPES in virulence in vivo, the integrative plasmid pLEXSYHygR was used to overexpress the PES homologue in L. major parasites. LmjPES sequence was obtained from L. major cDNA with both primers, LmjPESpLEXSYFw and LmjPESpLEXSYRv, and then inserted into pLEXSY-HygR plasmid (Figure 6A-B) as described in 
the Material and methods section. Following the strategy previously described, the sequence target gene was integrated by homologous recombination into the chromosomal 18SrRNA (ssu) locus (Figure 6A) and then transcribed by RNA polymerase I. LmjPES gene expression levels were measured by qPCR. One clone overexpressing ten times more $(10.36 \pm 0.06)$ than control (cells harbouring pLEXSY-HygR plasmid) was selected for in vivo infections (Figure 6C).

A

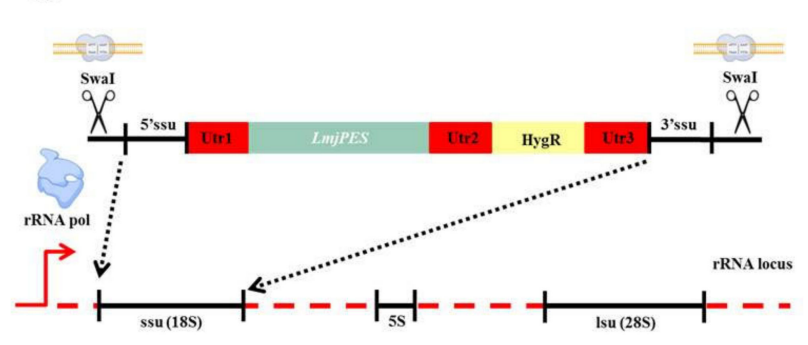

B

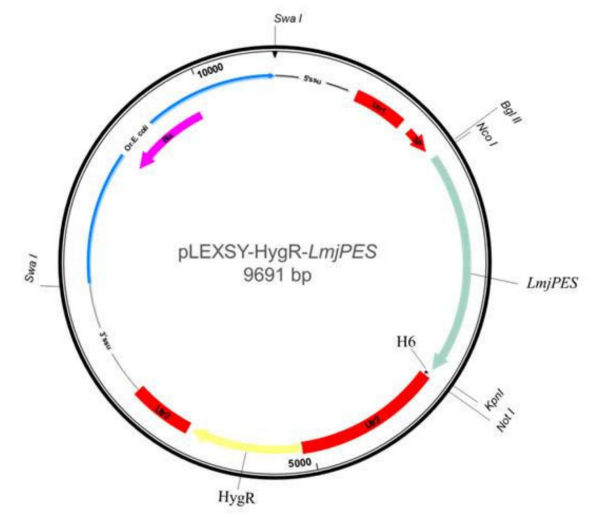

C

LmjPES

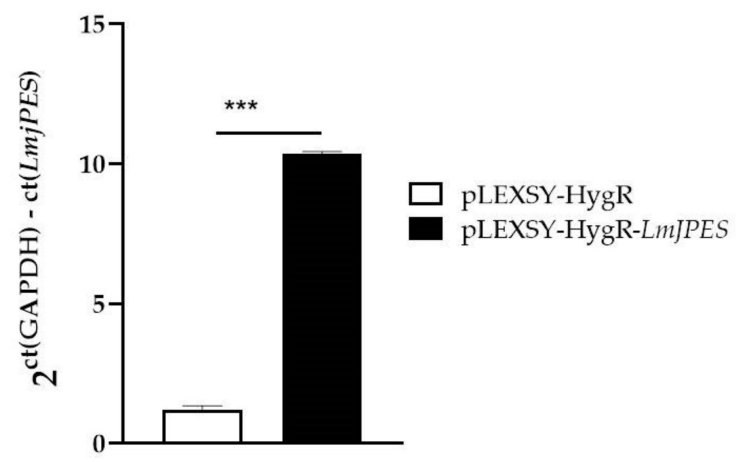

Figure 6. Generation of Leishmania major strains overexpressing LmjPES. (A) Schematic representation of the approach to overexpress LmjPES by the integration of pLEXSY-HygR plasmid harboring LmjPES sequence (pLEXSY-HygR-LmjPES) in the 18S rRNA locus. (B) Map of the integrative plasmid carrying the LmjPES sequence used to generate overexpressing parasites. (C) LmjPES gene expression level of transgenic L. major strains (pLEXSY-HygR-LmjPES) compared to L. major control (pLEXSY-HygR) parasites. The LmjPES expression level of recombinant parasites was checked by quantitative real-time PCR (qPCR) and represented $\left.{ }^{* * *} p<0.001\right)$.

Female BALB/c mice were subcutaneously inoculated in the right footpad with three low-dose inoculations of PNA selected metacyclic promastigotes once a week, and the inflammation was monitored weekly (Figure 7A) until the end of the experiment. A slight swelling was detectable in infected animals two weeks after the last inoculation. As illustrated in Figure 7B-C, overexpressing parasites caused a larger area of inflammation compared to control. Four weeks after the last inoculation, the footpad inflammation was higher in animals infected with the overexpressing strains, and such differences were statistically significant by the end of the assay (Figure 7A-D). To assess whether the overexpression of LmjPES would induce an increase in lesion size $(>0.60 \mathrm{~mm})$, we carried out an additional study. Lesions were allowed to grow until day 35 (five weeks) after the last inoculation. It was observed that the percentage of animals displaying a significant lesion size $(>0.60 \mathrm{~mm}$ ) was $0 \%, 47.62 \%$, and $65.63 \%$, for the uninfected, positive controls (pLEXSY-HygR), and pLEXSY-HygR-LmjPES infected mice, respectively (Figure 7E). The curves were statistically different when compared to that of the pLEXSY-HygR-LmjPES 
group $(* * *<0.001)$, as assessed by log-rank (Mantel-Cox) analysis (Figure 7E). The median time (MT) to overcome a lesion size of $0.60 \mathrm{~mm}$ was four weeks in the pLEXSYHygR-LmjPES group (MT $=4$ weeks, lesion size $>0.60 \mathrm{~mm}$ in $100 \%$ of the animals), whereas such lesion sizes in the uninfected and pLEXSY-HygR groups remained almost unchanged (lesion size was $<0.60 \mathrm{~mm}$ in more than $60 \%$ of mice after five weeks) (Figure 7E). Thus, an increased expression of LmjPES in L. major-infected mice correlated with a significantly higher lesion size.

A

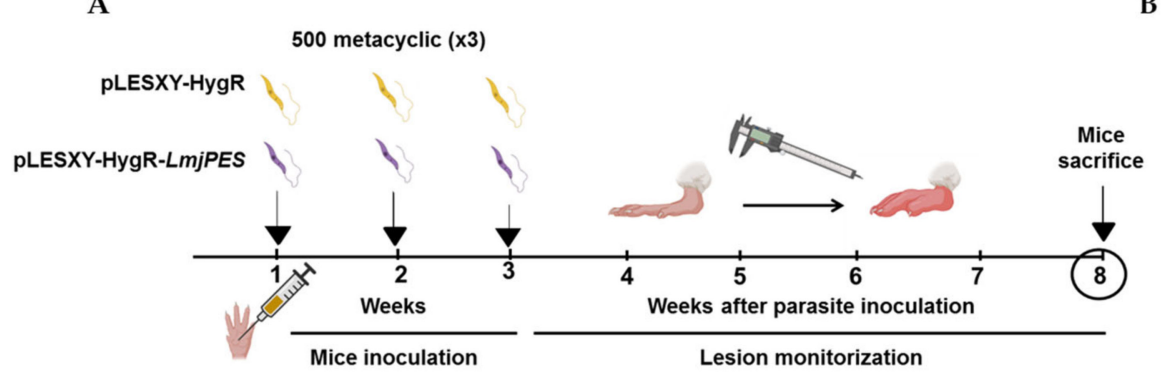

C

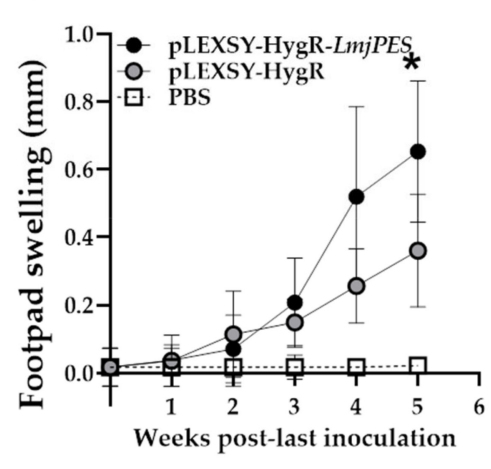

D

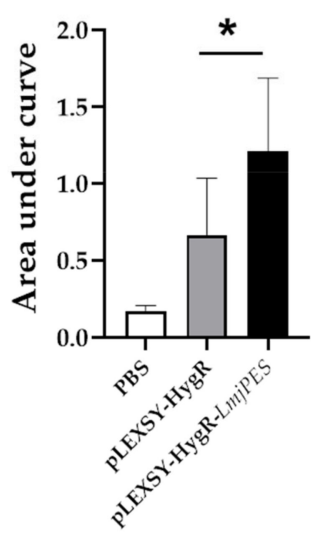

E
B

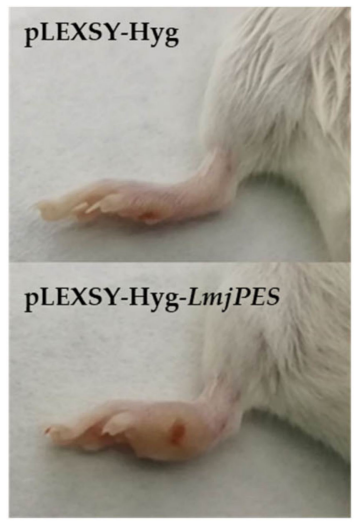

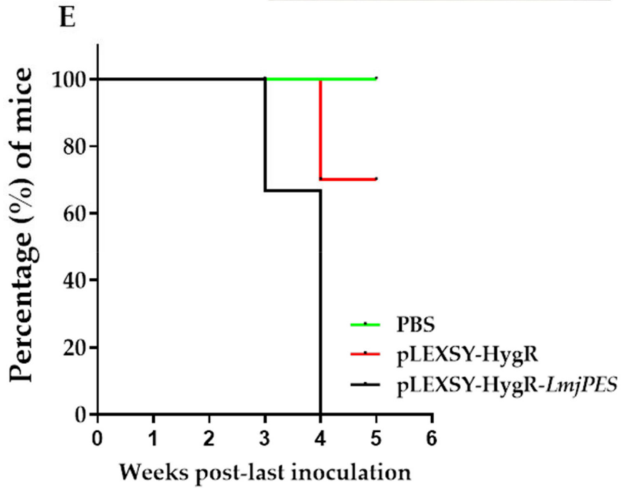

Figure 7. LmjPES overexpressing parasites exhibited higher and faster footpad inflammation in BALB/c mice than nonoverexpressing parasites. (A) Schematic representation of the experimental setting. During the inoculation period, animals were subcutaneously infected in the right footpad with 500 metacyclic parasites, overexpressing (pLEXSY-HygR-LmjPES) or non-overexpressing control (pLEXSY-HygR) LmjPES. Three cycles of inoculation were carried out once a week. After the last inoculation, the swelling was measured weekly until the end of the experiment (lesion monitorization). (B) Representative images of inoculated footpads of mice infected with parasites overexpressing (pLEXSY-HygR-LmjPES) or control (pLEXSYHygR) LmjPES. (C) Footpad swelling measured weekly until five weeks after the last parasite inoculation with both pLEXSY-HygR and pLEXSY-HygR-LmjPES strains. (D) Area under the curve for footpad swelling from uninfected (PBS) mice and inoculated with pLEXSY-HygR and PLEXSY-HygR-LmjPES parasites. (E) Percentage of mice with no significant lesion development after being infected by LmjPES overexpressing (pLEXSY-HygR-LmjPES) and non-overexpressing parasites (pLEXSY-HygR). Significant lesion was defined as a swelling $>0.6 \mathrm{~mm}$. Survival curves were calculated with PRISM version 5.0. The bars represented the means $( \pm \mathrm{SD})\left({ }^{*} p<0.05\right)$.

\subsection{In Vivo Infection with LmjPES Overexpressing Parasites Induced a Higher Production of iNOS in the Inoculation Area}

The staining of hematoxylin-eosin footpad sections was also analyzed. It showed the general layout and distribution of cells and provided an overview of tissue sample structure. A higher infiltrate area was observed in mice infected with LmjPES-overexpressing parasites compared to those inoculated with pLEXSY-HygR-harboring Leishmania (Figure 8A-B). In 
addition, an immunohistochemical analysis of iNOS protein in the footpad section of mice was performed at the end of the experiment. As observed in Figure 8, five weeks after the last inoculation, iNOS staining was significantly higher in footpad sections from mice infected with LmjPES overexpressing parasites compared to the levels of protein in animals inoculated with control (cells harboring pLEXSY-HygR plasmid) (Figure 8B).

A
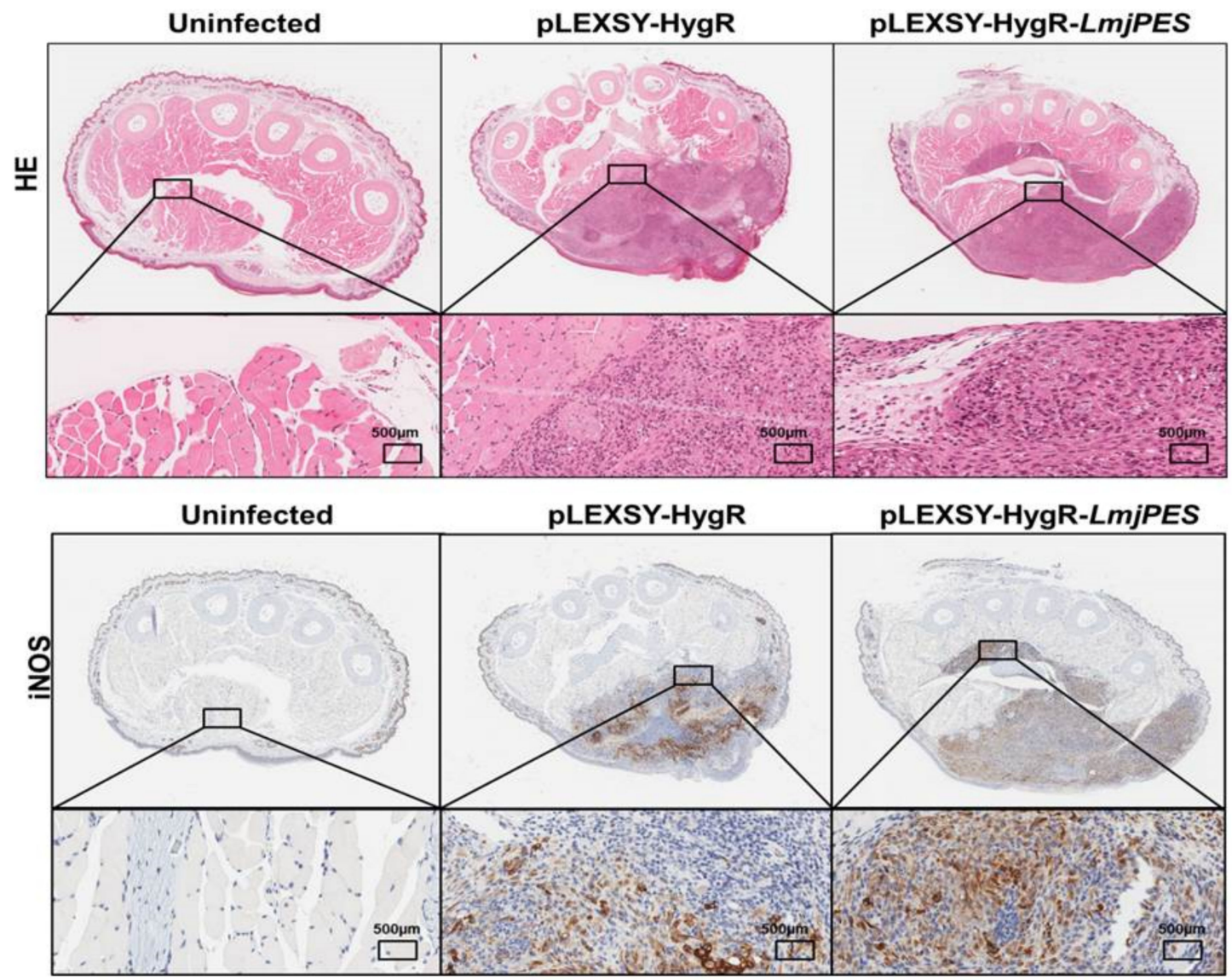

B

iNOS

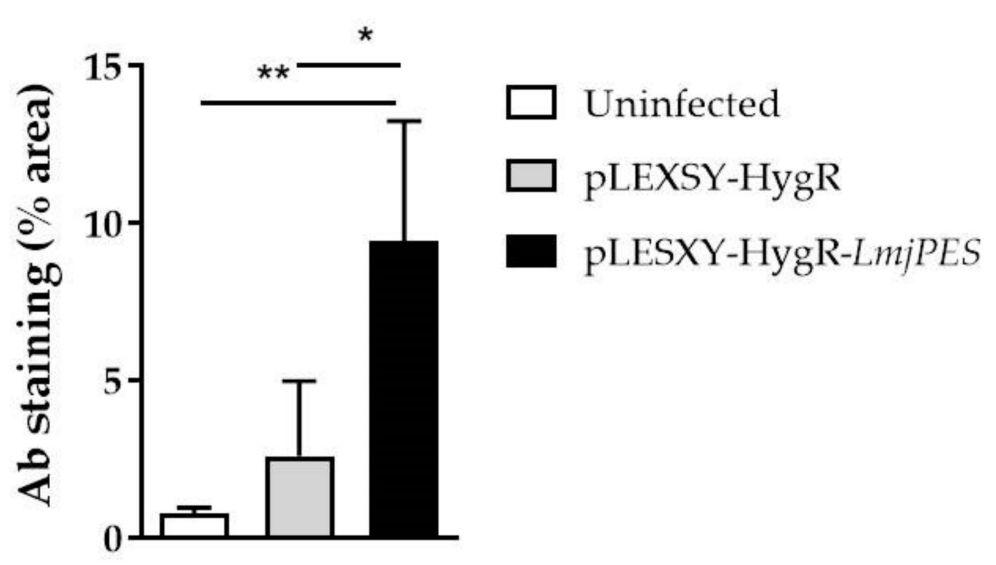

Figure 8. Histopathology and immunohistochemistry results of the footpad sections. Five weeks after last inoculation, animals were sacrificed to determine the footpad inflammation by histology staining methods. (A) Hematoxylin-eosin and immunohistochemical staining for iNOS in footpad sections from mice infected with LmjPES-overexpressing and nonoverexpressing parasites. (B) The differences in the area of footpad sections stained with antibodies of iNOS from animals infected with LmjPES-overexpressing parasites compared to those inoculated with control (cells harboring pLEXSY-HygR plasmid). The bars represented the means $( \pm \mathrm{SD})\left({ }^{*} p<0.05,{ }^{* *} p<0.01\right)$. 


\section{Discussion}

The Leishmania genus comprises heteroxenous parasites which acquire the capability to infect vertebrates through morphological and molecular changes. In the present work, the pescadillo homolog from Leishmania parasites has been firstly characterized and related with parasite in vitro and in vivo infective processes.

The Pescadillo (PES) gene was first discovered as a site of a retrovirus-insertion mutation that caused severe defects during embryogenesis in Zebrafish [32]. This gene has also been related to several cell processes, such as embryo development, cell proliferation, ribosome biogenesis, cancer and virulence acquisition [14-16,18,21,33-35]. Interestingly, based on its sequence and function among species, PES product is a well-conserved protein. Moreover, its homologues have been identified and functionally well characterized in the human (PES1), yeast (YPH1, Nop7p), and mouse (Pes1) proteomes [36,37]. However, this protein has never been studied or analyzed within trypamosomatids, including Leishmania parasites. The genome availability of several Leishmania species allowed us to detect the presence of PES homolog in L. major (LmjPES). Due to its high conservation and the importance of the cellular processes in which PES protein is involved, we aimed to study its role in Leishmania parasites. The sequence analysis of the conserved motifs and prediction based on alignments showed that LmjPES protein has an evolutionary highly conserved $\mathrm{N}$-terminal domain of pescadillo-like proteins (NPLP-domain) composed of 260 amino acids. These domains have traditionally been related to proteins involved in ribosome biogenesis $[38,39]$. In fact, previous studies have demonstrated the role of the NPLP domain in PES1 incorporation to PeBoW complex through its interaction with Bop1 $[38,39]$. The PeBoW complex is essential for cell proliferation and maturation of the large ribosomal subunit in mammalian cells [40]. It is composed of PES1, Bop1 and WDR12 proteins or their yeast homologues, Nop7, Erb1 and Ytm1, respectively [39]. Ribosome biogenesis is a fundamental process that is tightly related to cell growth and proliferation.

NPLP-domain within LmjPES is followed by a BRCT fragment, which belongs to a complex group of protein domains first described in the tumour-suppressor protein BRCA1. $\mathrm{BRCT}$ domains are DNA/protein binding modules mostly implicated in cell processes such as DNA Damage Response (DDR), DNA repair, and/or cell cycle control [41] in a wide range of organisms from bacteria to mammals. BRCT from PES protein has been reported as being responsible for PeBow complex assembly. Additionally, in DNA repair and the cell cycle proteins harboring these domains are involved in pathways such as ribosomal RNA processing and protein interaction in a phospho-dependent manner [42-44]. These data suggest that PES protein may have functions beyond ribosome biogenesis. Interestingly, a merozoite adhesive erythrocytic binding ligand (MAEBL) was recently identified at the C-terminal. This domain was first reported in rodent malaria parasites as part of a protein family from the apical organelle of merozoites, which is involved in erythrocyte invasion [45]. To our knowledge, it is the first time that this domain has been reported in Leishmania. Further research will be needed to determine if the LmjPES MAEBL domain performs a similar function, or if it is just an evolutionary footprint from non-conserved domains. Since this domain belongs to proteins involved in host cell adhesion, and the adhesion process is critical during infectivity, the presence of the aforementioned domain in LmjPES could show that this protein plays a role in the infectivity process within Leishmania biology.

The nuclear localization of LmjPES was initially predicted by the presence of Nuclear Location Signals (NLS) in the sequence of the protein, specifically located in the C-terminal region. We further demonstrated that LmjPES is a nucleus-located protein, supporting previous results showing the nuclear location of PES homologues.

It is well known that ribosomal proteins can exhibit extra ribosomal functions [46]. We therefore explored additional functions of PES in Leishmania major. LmjPES gene expression in metacyclic parasites was significantly higher when compared to its level in procyclics. Thus, it might be involved in Leishmania infectivity, since it is mainly expressed in the infective forms. Similarly, previous research demonstrated the implication of a PES 
homolog from Candida albicans in both in vitro and in vivo virulence [21,34]. On the other hand, in Plasmodium falciparum a PES ortholog (PfPES) has been identified during the characterization of the first dual phosphatase as a protein, showing significantly increased levels from ring to trophozoite [22]. Although multiple alignments revealed that PfPES contained domains of PES proteins such as BRCT and NLS, our studies illustrated that PfPES and LmjPES are phylogenetically distant. Since it is mainly expressed in the infective forms, LmjPES might be involved in Leishmania infectivity. When murine peritoneal macrophages were infected with LmjPES overexpressing parasites, we observed increased infectivity ratios in correlation with higher LmjPES expression levels after the infection. Our data suggested that this gene might be implicated in the infectious capability of the parasites. In vivo analyses showed similar evidences. To induce such overexpression, $L$. major parasites were transfected with a constitutive expression vector harboring LmjPES sequence. pLEXSY-HygR-LmjPES infected mice showed significantly higher footpad thickness than that of pLEXSY-HygR infected mice. Accordingly, hematoxylin-eosin staining presented a higher infiltration area in footpads from LmjPES-overexpressing infected mice relative to control footpads. An increase of the susceptibility to L. major generally occurred after the sub-cutaneous (s.c.) inoculation of a relatively high number of parasites into BALB/c mice, and therefore the induction of the early T helper 2 (Th2) response [47,48]. Consequently, infected mice usually succumbed to parasite visceralization. In the present study, mice were inoculated three times in successive weeks with infective metacyclic promastigotes, as previously described [49]; the spleen and lymph nodes were not infected. On the other hand, high iNOS detection corresponding to increased cell infiltration at the site of infection with Leishmania has been previously detected [49-52]. This is likely due to the recruitment of NOS-producing cells to the site of infection during cutaneous leishmaniasis when inflammation occurred [53-56].

Certain ribosomal proteins from Leishmania parasites have been described as antigens detected by the host immune system $[57,58]$. In addition, Leishmania ribosomal proteins combined with $\mathrm{CpG}$ oligodeoxynucleotides have demonstrated effectiveness as vaccination against primary [59] and secondary infection [60]. The acquired protection was associated with the induction of an IL-12 dependent specific-IFN- $\gamma$ [59]. IFN $\gamma$ and tumour necrosis factor (TNF) acted synergistically to promote the activation of macrophages through the induction of iNOS [61], which was essential to control the burden of Leishmania parasites by the production of reactive oxygen species (ROS). In fact, the increased tissue expression of iNOS has been closely associated with resistance to L. major [62]. In our study, high iNOS protein production was detected in the footpad of pLEXSY-HygR-LmjPES-infected mice five weeks after the last inoculation. This might be due to the putative antigenic nature of PES homologue, since some parasite antigens are conserved intracellular proteins like heat shock proteins, histones or ribosomal proteins [59].

Furthermore, as part of PebOW complex, PES has been related to cell proliferation through its involvement in the cell cycle [16]. It has been observed that growth arrest during PES1 depletion was caused by the disruption of rRNA processing, leading to the activation of a nucleolar stress cell cycle checkpoint, or to the depletion of ribosome and the alteration of translation [21]. Similarly, PES1 protein has been demonstrated to play a key role in oncogenic transformation and tumor progression. For instance, PES1 expression was suppressed in confluent Hela cells, associated with a reduced proliferation, while early passage Hela cells exhibited higher expression levels of PES1 [36]. Ribosomal proteins are frequently upregulated in tumors and mutations in genes encoding for proteins that regulate rRNA synthesis [63]. Moreover, nucleolar stress is considered a potential anticancer therapy [64], and this phenomenon is produced in trypanosomatids by transcription inhibitors through the agglomeration of RNA binding proteins $[65,66]$. Interestingly, there are specific drugs which have shown an ability to decrease transcript levels of PES1 [12] as a mechanism of action. The targeting of PES remains an emerging therapeutic strategy. 


\section{Materials and Methods}

\subsection{Nucleotide and Amino Acid Sequence Alignments}

Nucleotide and genomic sequence data from the kinetoplastid homologs of PES and the PES protein orthologous sequences were obtained from TriTrypDB [67]. Other kinetoplastid protein sequences not found in TriTrypDB were retrieved through the Basic Local Alignment Search Tool (BLAST) programs using the NCBI reference protein database and EuPathDB35. The L. major protein sequence (XP_888589.1) was used as the query sequence for BLAST searches. Multiple sequences alignments were performed using the BLOSUM62 matrix implemented in CLUSTALW program.

\subsection{Assessment of Secondary Structure and Post-Translational Modifications}

The secondary structure overview from LmjPES was predicted using Quick2D, implemented in MPI Bioinformatics Toolkit [68]. LmjPES disordered regions were inspected by the Meta-Disorder (MD) method [69] from the PredictProtein server [70]. The protein function was deduced by InterPro protein sequence analysis and classification [71]. Conserved domains and families were identified using the Pfam database from the European Bioinformatics Institute [72] (Uniprot accession number: 097209). The following tools were used to assess post-translational modifications: the NetNGlyc 1.0 server46 from the Technical University of Denmark was used for N-terminal glycosylation prediction [73]; the MYR Predictor of the IMP Bioinformatics Group assessed PES sequences for possible myristoylation patterns [74]; the TMHMM Server v2.0 from the Technical University of Denmark was used to determine protein transmembrane regions [75]; ProtParam [76] was used to predict the molecular mass of the protein and its theoretical isoelectric point; phosphorylation sites were assessed by neural network prediction using the NetPhos 2.0 server [77], which identifies serine, threonine, and tyrosine phosphorylation sites; the prediction of the signal peptide and cleavage site was performed using the SignalP 4.0 server [78]; the Nuclear Localization Signal (NLS) was predicted by cNLS mapper [79]; and the protein diagram was drawn by using DOG 1.0: Illustrator of Protein Domain Structures [80].

\subsection{Phylogenetic Analysis}

Protein-protein Basic Local Alignment Search Tool (BLASTP) was used to retrieve the ortholog sequences of LmjPES (XP_888589.1) protein. Multiple sequence alignment was performed using MUSCLE v3.8.31 [81,82], as implemented in the European Molecular Biology Laboratory-European Bioinformatics (EMBL-EBI) web server [83]. This alignment was then used to construct a phylogenetic tree by using the Maximum Likelihood method and a JTT matrix-based model [84]. Initial trees for the heuristic search were obtained automatically by applying Neighbor-Join and BioNJ algorithms to a matrix of pairwise distances estimated using the JTT model, and then selecting the topology with superior log likelihood value. The analysis involved 14 amino acid sequences. All positions containing gaps were eliminated, generating a final dataset with a total of 62 positions. The tree was rooted using the sequence of a hypothetical protein, C923_03267 from Plasmodium falciparum. Evolutionary analyses were conducted in MEGA X [85].

\subsection{Parasites and Animals}

L. major parasites (Lv39c5) were maintained as previously described [86]. For infection experiments and to preserve their infectivity, parasites were obtained from infected BALB/c mouse spleen and maintained in culture with Schneider's medium for no more than five passages [87]. Animal studies were performed with female BALB/c mice and all the procedures were approved by the Animal Care Ethics Commission of the University of Navarra (approval number: E24/18(068/15) 10 August 2018). 


\subsection{Genetic Manipulation of Leishmania major}

The plasmids pXG-mCherry 34, pXG-HygR and pLEXSY-HygR were used in this study. Plasmid pXG-mCherry34 was assembled as reported [88]. The coding DNA sequence (CDS) corresponding to LmjPES was amplified by PCR from L. major genomic DNA with the primers LmjPESmCherry-Fw and LmjPESmCherry-Rv, LmjPESpXG-Fw and LmjPESpXG-Rv, and LmjPESpLEXSY-Fw and LmjPESpLEXSY-Rv (Table 1), for insertion in pXG-mCherry34, pXG-HygR and pLEXSY-HygR, respectively. LmjPES PCR products were then ligated into $\mathrm{pCR}^{\circledR}$ 2.1-TOPO ${ }^{\circledR}$ (ThermoFisher Scientific, Rockville, MD, USA) cloning vector. Plasmids were digested with the following restriction enzymes: NotI-HF (New England Biolabs, Ipswich, MA, USA) for the pXG-LmjPES-mCherry34 construct, BamHI (Takara, Tokyo, Japan) for the pXG-HygR-LmjPES construct, and NcoI (New England Biolabs, Ipswich, MA, USA) and KpnI (New England Biolabs, Ipswich, MA, USA) for the pLEXSY-HygR-LmjPES construct. These digestions were gel purified using QIAquick ${ }^{\circledR}$ Gel Extraction Kit $\left(\right.$ Qiagen $^{\mathrm{TM}}$ ) following the manufacturer's protocol, and then ligated using T4 Ligase (Invitrogen ${ }^{\mathrm{TM}}$ ). LmjPES sequences and orientation within pXG-LmjPES-mCherry34 and pXG-HygR-LmjPES were confirmed by PCR and sequencing. pLEXSY-HygR-LmjPES plasmid was linearized by digestion with SwaI (New England Biolabs, Ipswich, MA, USA) before electroporation [89]. pLEXSY-INT primers (Table 1) were used to confirm pLEXSY-HygR-LmjPES integration in the 18S rRNA locus.

Table 1. Primer sequences employed for the genetic manipulation of Leishmania parasites.

\begin{tabular}{|c|c|c|}
\hline Name & Forward $(\mathrm{Fw})$ Primer $\left(5^{\prime} \rightarrow 3^{\prime}\right)$ & Reverse (Rv) Primer $\left(5^{\prime} \rightarrow 3^{\prime}\right)$ \\
\hline LmjPESmCherry & GCGGCCGCTATTATGGTCACATAAGAAGCAG & GCGGCCGCATTACTGCACCCACTT \\
\hline LmjPESpXG & GCCGGATCCCCACCAATGGTCCATAAGAAGCAGGCA & GCCGGATCCTTACTGCACCCACTTGGGCAG \\
\hline LmjPESpLEXSY & CCATGGGAAATGGTCCATAAGAAGCAGGCA & GGT ACC CTG CAC CCA CTT GGG CAG TTT \\
\hline pLEXSY-INT & CCGACTGCAACA AGGTGTAG & CAT CTA TAG AGA AGT ACA CGT AAA AG \\
\hline qLMjPES & GAGATGGACATGGAGGACGA & TCATCTCGCGCTG \\
\hline qGAPDH & CATCAAGTGCGTGAAGGCGC & CGTCGGCGAGTACTCGTGCTG \\
\hline
\end{tabular}

\subsection{Fluorescence Microscopy}

A total number of $2 \times 10^{7}$ log-phase pXG-mCherry34-LmjPES L. major promastigotes were fixed using a $1 \%$ paraformaldehyde/phosphate-buffered saline (PBS; Gibco Laboratories) solution. Then, cells were stained with a $1 \mathrm{mg} / \mathrm{mL}$ DAPI (Sigma Aldrich, St. Louis, $\mathrm{MO}, \mathrm{USA}$ ) solution ( $30 \mathrm{~min}$ at $4{ }^{\circ} \mathrm{C}$ ) and washed twice with PBS. Images from the slides were acquired in a PerkinElmer ultraVIEW confocal microscope.

\subsection{In Vitro Infections}

Murine peritoneal macrophages extracted as previously described [87] were seeded in 8-well culture chamber slides (Lab- TekTM; BD Biosciences) at a density of $5 \times 10^{4}$ cells per well in Roswell Park Memorial Institute (RPMI) medium and allowed to adhere overnight at $37^{\circ} \mathrm{C}$ in a $5 \% \mathrm{CO}_{2}$ incubator. Metacyclic L. major promastigotes harbouring pXG-HygR or pXG-HygR-LmjPES plasmids and isolated by the peanut agglutinin (PNA) method [90] were used to infect macrophages at a macrophage/parasite ratio of $1 / 20$, and incubated at $37{ }^{\circ} \mathrm{C}$ in a $5 \% \mathrm{CO}_{2}$ atmosphere. Chamber slides were washed with PBS, fixed with methanol three and six hours post-infection, and finally stained with Giemsa. The number of amastigotes per macrophage was evaluated by light microscopy (200 infected cells were analyzed in each well).

\subsection{In Vivo Infections}

BALB/c mice were distributed in three groups; mice from one group were PBS inoculated, and two groups were infected with LmjPES overexpressing parasites (pLEXSYHygR-LmjPES) and control parasites (pLEXSY-HygR), respectively. The animals were subcutaneously inoculated as reported [49]. Footpad swelling was quantified weekly with a caliper, and the swelling was determined as the difference between the infected and 
non-infected footpad. Five weeks after the last inoculation, animals were euthanized. For immunohistochemistry determination, footpads were placed in $4 \%(w / v)$ formaldehyde (PanReac, Barcelona, Spain) and then formalin-fixed.

\subsection{RNA Extraction and Gene Expression Analysis}

A stationary phase culture was used to select metacyclic parasites by PNA method as previously described [91]. Total RNA extraction, retrotranscription and qPCR assays were performed as reported [49]. Primers qLmjPES-Fw and qLmjPES-Rv and, primers qGAPDH-Fw and qGAPDH-Rv were used to amplify LmjPES and glyceraldehyde-3-phosphate dehydrogenase (GAPDH) housekeeping gene [87], respectively, in Leishmania parasites (Table 1). The relative quantification of gene expression was calculated by the $2^{\text {ct(GAPDH)-ct(gene) }}$ method [49].

\subsection{Immunohistochemistry Analysis:}

Immunohistochemistry studies were performed as previously described [49], using the primary antibody rabbit anti-iNOS (1:400; Abcam, ab15323). Fiji 2.0 software was used for analysis [91].

\subsection{Statistical Analyses}

Statistical studies were executed with GraphPad Prism v7. The analyses were performed using the non-parametric Kruskal-Wallis and Mann-Whitney U tests. All $p$ values were two-tailed and considered significant if $p<0.05$. Data were represented as mean \pm SD. Experimental differences between groups were studied by one-way ANOVA (or by unpaired $t$ test, in the case of two comparisons). Lesion sizes were compared by the log-rank (Mantel-Cox) test. The median time to develop a significant lesion (size $>0.6 \mathrm{~mm}$ ) was estimated with Kaplan-Meier analysis. $p$-values were considered significant when ${ }^{*} p<0.05,{ }^{* *} p<0.01,{ }^{* * *} p<0.001$ and ${ }^{* * * *} p<0.0001$.

\section{Conclusions}

In conclusion, the present work shows the relation between the newly discovered homologue of PES in Leishmania parasites with infectivity capability in vitro and virulence in vivo. On the one hand, transgenic parasites overexpressing LmjPES were able to infect a higher percentage of macrophages during in vitro infection. On the other hand, LmjPES expression in L. major parasites produced an increase in cell recruitment at the inoculation site during in vivo studies in BALB/c mice. Further studies are needed to better understand the role of this newly discovered gene in leishmaniasis outcomes. However, due to its relevant implications for parasite virulence, LmjPES might be considered a promising target for new drug design against leishmaniasis.

Supplementary Materials: The following are available online at https:/ /www.mdpi.com/article/10 $.3390 /$ ijms222212592/s1.

Author Contributions: Conceptualization, M.A., C.F.-R., E.L. and P.A.N.; Methodology, M.A., C.F.-R., K.M., J.P.-G., A.V., E.L. and P.A.N.; Validation, M.A., C.F.-R., K.M., J.P.-G., A.V., E.L., and P.A.N.; Formal analysis, M.A., C.F.-R., E.L. and P.A.N.; Investigation, M.A., C.F.-R., K.M., J.P.-G., A.V., E.L., and P.A.N.; Resources, P.A.N.; Writing-original draft preparation, M.A., C.F.-R., E.L. and P.A.N.; writing - review and editing, C.F.-R., E.L. and P.A.N.; Visualization, M.A., C.F.-R., E.L. and P.A.N.; Supervision, P.A.N.; Project administration, P.A.N.; Funding acquisition, P.A.N. All authors have read and agreed to the published version of the manuscript.

Funding: This research was funded by the Spanish Ministry of Science and Innovation (PID2020112713RB-C21), Fundación La Caixa (LCF/PR/PR13/11080005), Fundación Caja Navarra, Gobierno de Navarra-Salud (12/2017), Fundación Roviralta, and Ubesol. J.P.G. thanks the Spanish “Ministerio de Educacion Cultura y Deporte" (PhD fellowship FPU17/03304).

Institutional Review Board Statement: Not applicable.

Informed Consent Statement: Not applicable. 


\section{Data Availability Statement: Not applicable.}

Acknowledgments: We acknowledge COST Actions CA18217 and CA18218, and EU Project unCoVer (DLV-101016216) for their support. We also thank Guillermo Martinez de Tejada, Hawraa Shahrour and Pablo Rosas Val for their scientific assistance.

Conflicts of Interest: The authors declare no conflict of interest.

\section{References}

1. Molyneux, D.H.; Asamoa-Bah, A.; Fenwick, A.; Savioli, L.; Hotez, P. The history of the neglected tropical disease movement. Trans. R. Soc. Trop. Med. Hyg. 2021, 115, 169-175. [CrossRef]

2. $\quad$ Engels, D.; Zhou, X.-N. Neglected tropical diseases: An effective global response to local poverty-related disease priorities. Infect. Dis. Poverty 2020, 9, 10. [CrossRef]

3. Institute of Medicine (US) Forum on Microbial Threats. The Causes and Impacts of Neglected Tropical and Zoonotic Diseases: Opportunities for Integrated Intervention Strategies. Washington (DC): National Academies Press (US); 2011. Workshop Overview. Available online: https:/ / www.ncbi.nlm.nih.gov/books/NBK62526/?log\$=activity (accessed on 23 September 2021).

4. World Health Organization. Observatory, T.G.H. Leishmaniasis . Available online: https://www.who.int/data/gho/data/ themes/topics/gho-ntd-leishmaniasis (accessed on 23 September 2021).

5. World Health Organization. Leishmaniasis. Available online: https://www.who.int/health-topics/leishmaniasis\#tab=tab_1 (accessed on 23 September 2021).

6. Balanã-Fouce, R.; Prada, C.F.; Requena, J.M.; Cushman, M.; Pommier, Y.; Álvarez-Velilla, R.; Escudero-Martínez, J.M.; CalvoÁlvarez, E.; Pérez-Pertejo, Y.; Reguera, R.M. Indotecan (LMP400) and AM13-55: Two novel indenoisoquinolines show potential for treating visceral leishmaniasis. Antimicrob. Agents Chemother. 2012, 56, 5264-5270. [CrossRef]

7. Cojean, S.; Houze, S.; Haouchine, D.; Huteau, F.; Lariven, S.; Hubert, V.; Michard, F.; Bories, C.; Pratlong, F.; Le Bras, J.; et al. Leishmania resistance to miltefosine associated with genetic marker. Emerg. Infect. Dis. 2012, 18, 704-706. [CrossRef]

8. Coelho, A.C.; Boisvert, S.; Mukherjee, A.; Leprohon, P.; Corbeil, J.; Ouellette, M. Multiple mutations in heterogeneous miltefosineresistant Leishmania major population as determined by whole genome sequencing. PLoS Negl. Trop. Dis. 2012,6, e1512. [CrossRef]

9. Sundar, S.; Singh, B. Emerging therapeutic targets for treatment of leishmaniasis. Expert Opin. Ther. Targets 2018, 22, 467-486. [CrossRef]

10. Holdt, L.M.; Stahringer, A.; Sass, K.; Pichler, G.; Kulak, N.A.; Wilfert, W.; Kohlmaier, A.; Herbst, A.; Northoff, B.H.; Nicolaou, A.; et al. Circular non-coding RNA ANRIL modulates ribosomal RNA maturation and atherosclerosis in humans. Nat. Commun. 2016, 7, 12429. [CrossRef]

11. Dannheisig, D.P.; Bächle, J.; Tasic, J.; Keil, M.; Pfister, A.S. The Wnt/ $\beta$-Catenin Pathway is Activated as a Novel Nucleolar Stress Response. J. Mol. Biol. 2021, 433, 166719. [CrossRef]

12. Ahn, C.S.; Cho, H.K.; Lee, D.-H.; Sim, H.-J.; Kim, S.-G.; Pai, H.-S. Functional characterization of the ribosome biogenesis factors PES, BOP1, and WDR12 (PeBoW), and mechanisms of defective cell growth and proliferation caused by PeBoW deficiency in Arabidopsis. J. Exp. Bot. 2016, 67, 5217-5232. [CrossRef]

13. Fan, P.; Wang, B.; Meng, Z.; Zhao, J.; Jin, X. PES1 is transcriptionally regulated by BRD4 and promotes cell proliferation and glycolysis in hepatocellular carcinoma. Int. J. Biochem. Cell Biol. 2018, 104, 1-8. [CrossRef]

14. Lerch-Gaggl, A.; Haque, J.; Li, J.; Ning, G.; Traktman, P.; Duncan, S.A. Pescadillo is essential for nucleolar assembly, ribosome biogenesis, and mammalian cell proliferation. J. Biol. Chem. 2002, 277, 45347-45355. [CrossRef] [PubMed]

15. Gessert, S.; Maurus, D.; Rössner, A.; Kühl, M. Pescadillo is required for Xenopus laevis eye development and neural crest migration. Dev. Biol. 2007, 310, 99-112. [CrossRef] [PubMed]

16. Cho, H.K.; Ahn, C.S.; Lee, H.-S.; Kim, J.-K.; Pai, H.-S. Pescadillo plays an essential role in plant cell growth and survival by modulating ribosome biogenesis. Plant J. 2013, 76, 393-405. [CrossRef] [PubMed]

17. Xie, W.; Feng, Q.; Su, Y.; Dong, B.; Wu, J.; Meng, L.; Qu, L.; Shou, C. Transcriptional regulation of PES1 expression by c-Jun in colon cancer. PLoS ONE 2012, 7, e42253. [CrossRef] [PubMed]

18. Xie, W.; Qu, L.; Meng, L.; Liu, C.; Wu, J.; Shou, C. PES1 regulates sensitivity of colorectal cancer cells to anticancer drugs. Biochem. Biophys. Res. Commun. 2013, 431, 460-465. [CrossRef] [PubMed]

19. Cheng, L.; Li, J.; Han, Y.; Lin, J.; Niu, C.; Zhou, Z.; Yuan, B.; Huang, K.; Li, J.; Jiang, K.; et al. PES1 promotes breast cancer by differentially regulating ER $\alpha$ and ER $\beta$. J. Clin. Invest. 2012, 122, 2857-2870. [CrossRef] [PubMed]

20. Jiang, Z.; Zhang, Y.; Chen, X.; Wang, Y.; Wu, P.; Wu, C.; Chen, D. microRNA-1271 impedes the development of prostate cancer by downregulating PES1 and upregulating ER $\beta$. J. Transl. Med. 2020, 18, 209. [CrossRef]

21. Shen, J.; Cowen, L.E.; Griffin, A.M.; Chan, L.; Köhler, J.R. The Candida albicans pescadillo homolog is required for normal hypha-to-yeast morphogenesis and yeast proliferation. Proc. Natl. Acad. Sci. USA 2008, 105, 20918-20923. [CrossRef]

22. Kumar, R.; Musiyenko, A.; Cioffi, E.; Oldenburg, A.; Adams, B.; Bitko, V.; Krishna, S.S.; Barik, S. A zinc-binding dual-specificity YVH1 phosphatase in the malaria parasite, Plasmodium falciparum, and its interaction with the nuclear protein, pescadillo. Mol. Biochem. Parasitol. 2004, 133, 297-310. [CrossRef] 
23. Brar, G.A.; Weissman, J.S. Ribosome profiling reveals the what, when, where and how of protein synthesis. Nat. Rev. Mol. Cell Biol. 2015, 16, 651-664. [CrossRef]

24. Thomson, E.; Ferreira-Cerca, S.; Hurt, E. Eukaryotic ribosome biogenesis at a glance. J. Cell Sci. 2013, 126, 4815-4821. [CrossRef] [PubMed]

25. Boulon, S.; Westman, B.J.; Hutten, S.; Boisvert, F.-M.; Lamond, A.I. The nucleolus under stress. Mol. Cell 2010, 40, $216-227$. [CrossRef] [PubMed]

26. Martínez-Calvillo, S.; Florencio-Martínez, L.E.; Nepomuceno-Mejía, T. Nucleolar Structure and Function in Trypanosomatid Protozoa. Cells 2019, 8, 421. [CrossRef] [PubMed]

27. Vacas, A.; Fernández-Rubio, C.; Algarabel, M.; Peña-Guerrero, J.; Larrea, E.; Rocha Formiga, F.; García-Sosa, A.T.; Nguewa, P.A. The Novel Serine/Threonine Protein Kinase LmjF.22.0810 from Leishmania major may be Involved in the Resistance to Drugs such as Paromomycin. Biomolecules 2019, 9, 723. [CrossRef]

28. Sádlová, J.; Price, H.P.; Smith, B.A.; Votỳpka, J.; Volf, P.; Smith, D.F. The stage-regulated HASPB and SHERP proteins are essential for differentiation of the protozoan parasite Leishmania major in its sand fly vector, Phlebotomus papatasi. Cell. Microbiol. 2010, 12, 1765-1779. [CrossRef]

29. Elias, M.C.; Marques-Porto, R.; Freymüller, E.; Schenkman, S. Transcription rate modulation through the Trypanosoma cruzi life cycle occurs in parallel with changes in nuclear organisation. Mol. Biochem. Parasitol. 2001, 112, 79-90. [CrossRef]

30. Berriman, M.; Ghedin, E.; Hertz-Fowler, C.; Blandin, G.; Renauld, H.; Bartholomeu, D.C.; Lennard, N.J.; Caler, E.; Hamlin, N.E.; Haas, B.; et al. The genome of the African trypanosome Trypanosoma brucei. Science 2005, 309, 416-422. [CrossRef]

31. El-Sayed, N.M.; Myler, P.J.; Bartholomeu, D.C.; Nilsson, D.; Aggarwal, G.; Tran, A.N.; Ghedin, E.; Worthey, E.A.; Delcher, A.L.; Blandin, G.; et al. The genome sequence of Trypanosoma cruzi, etiologic agent of chagas disease. Science 2005, 309, $409-416$. [CrossRef] [PubMed]

32. Auende, M.L.; Amsterdam, A.; Becker, T.; Kawakami, K.; Gaiano, N. Insertional mutagenesis in zebrafish identifies two novel genes, pescadillo and dead eye, essential for embryonic development. Genes Dev. 1996, 10, 3141-3155. [CrossRef]

33. Oeffinger, M.; Leung, A.; Lamond, A.; Tollervey, D.; Lueng, A. Yeast Pescadillo is required for multiple activities during 60S ribosomal subunit synthesis. RNA 2002, 8, 626-636. [CrossRef] [PubMed]

34. Uppuluri, P.; Chaturvedi, A.K.; Jani, N.; Pukkila-Worley, R.; Monteagudo, C.; Mylonakis, E.; Köhler, J.R.; Lopez Ribota, J.L. Physiologic expression of the Candida albicans pescadillo homolog is required for virulence in a murine model of hematogenously disseminated candidiasis. Eukaryot. Cell 2012, 11, 1552-1556. [CrossRef]

35. Thomas, C.; Gustafsson, J.-Å. Targeting PES1 for restoring the ER $\alpha / E R \beta$ ratio in breast cancer. J. Clin. Invest. 2012, 122, 2771-2773. [CrossRef] [PubMed]

36. Kinoshita, Y.; Jarell, A.D.; Flaman, J.M.; Foltz, G.; Schuster, J.; Sopher, B.L.; Irvin, D.K.; Kanning, K.; Kornblum, H.I.; Nelson, P.S.; et al. Pescadillo, a novel cell cycle regulatory protein abnormally expressed in malignant cells. J. Biol. Chem. 2001, 276, $6656-6665$. [CrossRef] [PubMed]

37. Haque, J.; Boger, S.; Li, J.; Duncan, S. a The murine Pes1 gene encodes a nuclear protein containing a BRCT domain. Genomics 2000, 70, 201-210. [CrossRef] [PubMed]

38. Lapik, Y.R.; Fernandes, C.J.; Lau, L.F.; Pestov, D.G. Physical and functional interaction between Pes1 and Bop1 in mammalian ribosome biogenesis. Mol. Cell 2004, 15, 17-29. [CrossRef] [PubMed]

39. Tang, L.; Sahasranaman, A.; Jakovljevic, J.; Schleifman, E.; Woolford, J.L., Jr. Interactions among Ytm1, Erb1, and Nop7 required for assembly of the Nop7-subcomplex in yeast preribosomes. Mol. Biol. Cell 2008, 19, 2844-2856. [CrossRef]

40. Grimm, T.; Hölzel, M.; Rohrmoser, M.; Harasim, T.; Malamoussi, A.; Gruber-Eber, A.; Kremmer, E.; Eick, D. Dominant-negative Pes1 mutants inhibit ribosomal RNA processing and cell proliferation via incorporation into the PeBoW-complex. Nucleic Acids Res. 2006, 34, 3030-3043. [CrossRef]

41. Callebaut, I.; Mornon, J.P. From BRCA1 to RAP1: A widespread BRCT module closely associated with DNA repair. FEBS Lett. 1997, 400, 25-30. [CrossRef]

42. Coquelle, N.; Green, R.; Glover, J.N.M. Impact of BRCA1 BRCT domain missense substitutions on phosphopeptide recognition. Biochemistry 2011, 50, 4579-4589. [CrossRef]

43. Sun, L.; Huang, Y.; Edwards, R.A.; Yang, S.; Blackford, A.N.; Niedzwiedz, W.; Glover, J.N.M. Structural Insight into BLM Recognition by TopBP1. Structure 2017, 25, 1582-1588.e3. [CrossRef]

44. Pessetto, Z.Y.; Yan, Y.; Bessho, T.; Natarajan, A. Inhibition of BRCT(BRCA1)-phosphoprotein interaction enhances the cytotoxic effect of olaparib in breast cancer cells: A proof of concept study for synthetic lethal therapeutic option. Breast Cancer Res. Treat. 2012, 134, 511-517. [CrossRef]

45. Kappe, S.H.; Noe, A.R.; Fraser, T.S.; Blair, P.L.; Adams, J.H. A family of chimeric erythrocyte binding proteins of malaria parasites. Proc. Natl. Acad. Sci. USA 1998, 95, 1230-1235. [CrossRef] [PubMed]

46. Bhavsar, R.B.; Makley, L.N.; Tsonis, P.A. The other lives of ribosomal proteins. Hum. Genomics 2010, 4, 327-344. [CrossRef]

47. Reithinger, R.; Dujardin, J.-C.; Louzir, H.; Pirmez, C.; Alexander, B.; Brooker, S. Cutaneous leishmaniasis. Lancet. Infect. Dis. 2007, 7, 581-596. [CrossRef]

48. Sacks, D.; Noben-Trauth, N. The immunology of susceptibility and resistance to Leishmania major in mice. Nat. Rev. Immunol. 2002, 2, 845-858. [CrossRef] 
49. Vacas, A.; Fernández-Rubio, C.; Larrea, E.; Peña-Guerrero, J.; Nguewa, P.A. LmjF.22.0810 from Leishmania major Modulates the Th2-Type Immune Response and Is Involved in Leishmaniasis Outcome. Biomedicines 2020, 8, 452. [CrossRef] [PubMed]

50. Oliveira, L.G.; Souza-Testasicca, M.C.; Vago, J.P.; Figueiredo, A.B.; Canavaci, A.M.C.; Perucci, L.O.; Ferreira, T.P.T.; Coelho, E.A.F.; Gonçalves, D.U.; Rocha, M.O.C.; et al. Annexin A1 Is Involved in the Resolution of Inflammatory Responses during Leishmania braziliensis Infection. J. Immunol. 2017, 198, 3227-3236. [CrossRef] [PubMed]

51. Rocha, F.J.S.; Schleicher, U.; Mattner, J.; Alber, G.; Bogdan, C. Cytokines, signaling pathways, and effector molecules required for the control of Leishmania (Viannia) braziliensis in mice. Infect. Immun. 2007, 75, 3823-3832. [CrossRef] [PubMed]

52. Cangussú, S.D.; de Souza, C.C.; Campos, C.F.; Vieira, L.Q.; Afonso, L.C.C.; Arantes, R.M.E. Histopathology of Leishmania major infection: Revisiting L. major histopathology in the ear dermis infection model. Mem. Inst. Oswaldo Cruz 2009, 104, 918-922. [CrossRef]

53. De Trez, C.; Magez, S.; Akira, S.; Ryffel, B.; Carlier, Y.; Muraille, E. iNOS-producing inflammatory dendritic cells constitute the major infected cell type during the chronic Leishmania major infection phase of C57BL/6 resistant mice. PLoS Pathog. 2009, 5, e1000494. [CrossRef]

54. Castro Gomes, C.M.; Sousa, M.G.T.; Menezes, J.P.B.; Batista, M.C.; Lima, A.C.S.; Belda, W.J.; Bradshaw, D.; Gama, M.E.A.; Laurenti, M.D.; Silveira, F.T.; et al. Immunopathological characterization of human cutaneous leishmaniasis lesions caused by Leishmania (Viannia) spp. in Amazonian Brazil. Parasitol. Res. 2017, 116, 1423-1431. [CrossRef] [PubMed]

55. Stenger, S.; Donhauser, N.; Thüring, H.; Röllinghoff, M.; Bogdan, C. Reactivation of latent leishmaniasis by inhibition of inducible nitric oxide synthase. J. Exp. Med. 1996, 183, 1501-1514. [CrossRef] [PubMed]

56. Olekhnovitch, R.; Ryffel, B.; Müller, A.J.; Bousso, P. Collective nitric oxide production provides tissue-wide immunity during Leishmania infection. J. Clin. Invest. 2014, 124, 1711-1722. [CrossRef] [PubMed]

57. Requena, J.M.; Alonso, C.; Soto, M. Evolutionarily conserved proteins as prominent immunogens during Leishmania infections. Parasitol. Today 2000, 16, 246-250. [CrossRef]

58. Cordeiro-Da-Silva, A.; Borges, M.C.; Guilvard, E.; Ouaissi, A. Dual role of the Leishmania major ribosomal protein S3a homologue in regulation of T- and B-cell activation. Infect. Immun. 2001, 69, 6588-6596. [CrossRef] [PubMed]

59. Iborra, S.; Parody, N.; Abánades, D.R.; Bonay, P.; Prates, D.; Novais, F.O.; Barral-Netto, M.; Alonso, C.; Soto, M. Vaccination with the Leishmania major ribosomal proteins plus $\mathrm{CpG}$ oligodeoxynucleotides induces protection against experimental cutaneous leishmaniasis in mice. Microbes Infect. 2008, 10, 1133-1141. [CrossRef]

60. Ramírez, L.; Iborra, S.; Cortés, J.; Bonay, P.; Alonso, C.; Barral-Netto, M.; Soto, M. BALB/c mice vaccinated with Leishmania major ribosomal proteins extracts combined with $\mathrm{CpG}$ oligodeoxynucleotides become resistant to disease caused by a secondary parasite challenge. J. Biomed. Biotechnol. 2010, 2010, 181690. [CrossRef] [PubMed]

61. Green, S.J.; Crawford, R.M.; Hockmeyer, J.T.; Meltzer, M.S.; Nacy, C.A. Leishmania major amastigotes initiate the L-argininedependent killing mechanism in IFN-gamma-stimulated macrophages by induction of tumor necrosis factor-alpha. J. Immunol. 1990, 145, 4290-4297.

62. Stenger, S.; Thüring, H.; Röllinghoff, M.; Bogdan, C. Tissue expression of inducible nitric oxide synthase is closely associated with resistance to Leishmania major. J. Exp. Med. 1994, 180, 783-793. [CrossRef]

63. Li, J.; Yu, L.; Zhang, H.; Wu, J.; Yuan, J.; Li, X.; Li, M. Down-regulation of pescadillo inhibits proliferation and tumorigenicity of breast cancer cells. Cancer Sci. 2009, 100, 2255-2260. [CrossRef]

64. James, A.; Wang, Y.; Raje, H.; Rosby, R.; DiMario, P. Nucleolar stress with and without p53. Nucleus 2014, 5, 402-426. [CrossRef]

65. Názer, E.; Sánchez, D.O. Nucleolar accumulation of RNA binding proteins induced by Actinomycin D is functional in Trypanosoma cruzi and Leishmania mexicana but not in T. brucei. PLoS ONE 2011, 6, e24184. [CrossRef]

66. Názer, E.; Verdún, R.E.; Sánchez, D.O. Nucleolar localization of RNA binding proteins induced by actinomycin D and heat shock in Trypanosoma cruzi. PLoS ONE 2011, 6, e19920. [CrossRef] [PubMed]

67. Aslett, M.; Aurrecoechea, C.; Berriman, M.; Brestelli, J.; Brunk, B.P.; Carrington, M.; Depledge, D.P.; Fischer, S.; Gajria, B.; Gao, X.; et al. TriTrypDB: A functional genomic resource for the Trypanosomatidae. Nucleic Acids Res. 2010, 38, D457-D462. [CrossRef]

68. Zimmermann, L.; Stephens, A.; Nam, S.-Z.; Rau, D.; Kübler, J.; Lozajic, M.; Gabler, F.; Söding, J.; Lupas, A.N.; Alva, V. A Completely Reimplemented MPI Bioinformatics Toolkit with a New HHpred Server at its Core. J. Mol. Biol. 2018, 430, 2237-2243. [CrossRef]

69. Schlessinger, A.; Punta, M.; Yachdav, G.; Kajan, L.; Rost, B. Improved disorder prediction by combination of orthogonal approaches. PLoS ONE 2009, 4, e4433. [CrossRef] [PubMed]

70. Yachdav, G.; Kloppmann, E.; Kajan, L.; Hecht, M.; Goldberg, T.; Hamp, T.; Hönigschmid, P.; Schafferhans, A.; Roos, M.; Bernhofer, M.; et al. PredictProtein-an open resource for online prediction of protein structural and functional features. Nucleic Acids Res. 2014, 42, W337-W343. [CrossRef]

71. Finn, R.D.; Attwood, T.K.; Babbitt, P.C.; Bateman, A.; Bork, P.; Bridge, A.J.; Chang, H.-Y.; Dosztányi, Z.; El-Gebali, S.; Fraser, M.; et al. InterPro in 2017-beyond protein family and domain annotations. Nucleic Acids Res. 2017, 45, D190-D199. [CrossRef]

72. Finn, R.D.; Coggill, P.; Eberhardt, R.Y.; Eddy, S.R.; Mistry, J.; Mitchell, A.L.; Potter, S.C.; Punta, M.; Qureshi, M.; Sangrador-Vegas, A.; et al. The Pfam protein families database: Towards a more sustainable future. Nucleic Acids Res. 2016, 44, D279-D285. [CrossRef]

73. Gupta, R.; Brunak, S. Prediction of glycosylation across the human proteome and the correlation to protein function. In Proceedings of the Pacific Symposium on Biocomputing, Kauai, HI, USA, 3-7 January 2002; pp. 310-322. 
74. The MYC Predictor. Available online: https://mendel.imp.ac.at/myristate/SUPLpredictor.htm (accessed on 23 September 2021).

75. Krogh, A.; Larsson, B.; von Heijne, G.; Sonnhammer, E.L. Predicting transmembrane protein topology with a hidden Markov model: Application to complete genomes. J. Mol. Biol. 2001, 305, 567-580. [CrossRef] [PubMed]

76. Wilkins, M.R.; Gasteiger, E.; Bairoch, A.; Sanchez, J.C.; Williams, K.L.; Appel, R.D.; Hochstrasser, D.F. Protein identification and analysis tools in the ExPASy server. Methods Mol. Biol. 1999, 112, 531-552. [CrossRef] [PubMed]

77. Blom, N.; Gammeltoft, S.; Brunak, S. Sequence and structure-based prediction of eukaryotic protein phosphorylation sites. J. Mol. Biol. 1999, 294, 1351-1362. [CrossRef] [PubMed]

78. Petersen, T.N.; Brunak, S.; von Heijne, G.; Nielsen, H. SignalP 4.0: Discriminating signal peptides from transmembrane regions. Nat. Methods 2011, 8, 785-786. [CrossRef] [PubMed]

79. Kosugi, S.; Hasebe, M.; Tomita, M.; Yanagawa, H. Systematic identification of cell cycle-dependent yeast nucleocytoplasmic shuttling proteins by prediction of composite motifs. Proc. Natl. Acad. Sci. USA 2009, 106, 10171-10176. [CrossRef]

80. Ren, J.; Wen, L.; Gao, X.; Jin, C.; Xue, Y.; Yao, X. DOG 1.0: Illustrator of protein domain structures. Cell Res. 2009, 19, $271-273$. [CrossRef]

81. Edgar, R.C. MUSCLE: Multiple sequence alignment with high accuracy and high throughput. Nucleic Acids Res. 2004, 32, 1792-1797. [CrossRef] [PubMed]

82. Edgar, R.C. MUSCLE: A multiple sequence alignment method with reduced time and space complexity. BMC Bioinform. 2004, 5, 113. [CrossRef] [PubMed]

83. Madeira, F.; Park, Y.M.; Lee, J.; Buso, N.; Gur, T.; Madhusoodanan, N.; Basutkar, P.; Tivey, A.R.N.; Potter, S.C.; Finn, R.D.; et al. The EMBL-EBI search and sequence analysis tools APIs in 2019. Nucleic Acids Res. 2019, 47, W636-W641. [CrossRef]

84. Jones, D.T.; Taylor, W.R.; Thornton, J.M. The Rapid Generation of Mutation Data Matrices From Protein Sequences. Comput. Appl. Biosci. 1992, 8, 275-282. [CrossRef] [PubMed]

85. Kumar, S.; Stecher, G.; Li, M.; Knyaz, C.; Tamura, K. MEGA X: Molecular Evolutionary Genetics Analysis across Computing Platforms. Mol. Biol. Evol. 2018, 35, 1547-1549. [CrossRef]

86. Fernández-Rubio, C.; Campbell, D.; Vacas, A.; Ibañez, E.; Moreno, E.; Espuelas, S.; Calvo, A.; Palop, J.A.; Plano, D.; Sanmartin, C.; et al. Leishmanicidal activities of novel methylseleno-imidocarbamates. Antimicrob. Agents Chemother. 2015, 59, 5705-5713. [CrossRef] [PubMed]

87. Fernández-Rubio, C.; Larrea, E.; Peña Guerrero, J.; Sesma Herrero, E.; Gamboa, I.; Berrio, C.; Plano, D.; Amin, S.; Sharma, A.K.; Nguewa, P.A. Leishmanicidal Activity of Isoselenocyanate Derivatives. Antimicrob. Agents Chemother. 2019, 63, e00904-18. [CrossRef] [PubMed]

88. Vacas, A.; Sugden, C.; Velasco-Rodriguez, O.; Algarabel-Olona, M.; Pena-Guerrero, J.; Larrea, E.; Fernandez-Rubio, C.; Nguewa, P.A. Construction of Two mCherry Plasmids (pXG-mCherry) for Transgenic Leishmania: Valuable Tools for Future Molecular Analysis. J. Parasitol. Res. 2017, 2017, 1964531. [CrossRef]

89. Cruz, A.; Coburn, C.M.; Beverley, S.M. Double targeted gene replacement for creating null mutants. Proc. Natl. Acad. Sci. USA 1991, 88, 7170-7174. [CrossRef]

90. Sacks, D.L.; Peter, V. Perkins Identification of an Infective Stage of Leishmania Promastigotes. Science 2011, 223, 1417-1419.

91. Schindelin, J.; Arganda-Carreras, I.; Frise, E.; Kaynig, V.; Longair, M.; Pietzsch, T.; Preibisch, S.; Rueden, C.; Saalfeld, S.; Schmid, B.; et al. Fiji: An open-source platform for biological-image analysis. Nat. Methods 2012, 9, 676-682. [CrossRef] 